\title{
Contar a los indígenas en Chile. Autoadscripción étnica en la experiencia censal de 1992 y $2002^{1}$
}

\author{
Hans Gundermann K. ${ }^{2}$, Jorge Iván Vergara del S. ${ }^{3}$ y Rolf Foerster G. ${ }^{4}$
}

\begin{abstract}
RESUMEN
Se analiza la conformación subjetiva de la autoadscripción étnica de los pueblos indígenas de Chile vista a través de los procesos censales de 1992 y 2002, de la acción institucional que se encuentra tras la definición y operación de registros étnicos, y de la información etnográfica. Se sostiene que en ambos censos, basados en declaraciones de autoadscripción sobre "cultura" y "pueblo", respectivamente, se manifiestan percepciones e identificaciones colectivas heterogéneas y en transformación. Para una interpretación de lo acaecido se acude a la diversa conformación sociohistórica de identificaciones y pertenencias colectivas entre los pueblos indígenas del país; asimismo, son considerados los rápidos cambios ocurridos en materia de conciencia y valoración de la diferencia cultural durante el período intercensal. También es importante el cambio de referencia de "cultura" a "pueblo", siendo la última semánticamente más restrictiva para sostener declaraciones de autoadscripción. Uno de los resultados relevantes del análisis es que se cumple sólo parcialmente el supuesto de una correspondencia entre autoadscripción étnica y base biográfica objetiva. Con ello, se hace evidente la debilidad de los procedimientos oficiales utilizados en Chile para "contar indígenas".
\end{abstract}

Palabras claves: Censo Nacional - autoadscripción étnicapertenencia cultural - identificación colectiva.

1 Este artículo es resultado del Proyecto FONDECYT 1020671: "Las contradicciones de la mediación. La Corporación Nacional de Desarrollo Indígena y el movimiento aymara y mapuche". Una versión preliminar fue presentada como ponencia en el Seminario Internacional "Derechos humanos y pueblos indígenas. Tendencias internacionales y la realidad chilena", organizado por el Instituto de Estudios Indígenas de la Universidad de la Frontera, Temuco, julio 20-22 de 2003.

2 Instituto de Investigaciones Arqueológicas y Museo R. P. Gustavo Le Paige s. j. (IIAM), Universidad Católica del Norte, San Pedro de Atacama. Casilla 17, Correo San Pedro de Atacama, II Región, CHILE. Email: hgunder@ucn.cl

3 Departamento de Ciencias Sociales, Universidad Arturo Prat. Centro de Investigaciones del Hombre en el Desierto (CIHDE). Av. Arturo Prat 2120, Iquique, CHILE. Email: jorge.vergara@unap.cl

4 Departamento de Antropología, Facultad de Ciencias Sociales, Universidad de Chile. Ignacio Carrera Pinto 1045, Ñuñoa, Santiago, CHILE. Email: rfoerste@uchile.cl

\begin{abstract}
This article analysis the subjective ethnic self-ascription of indigenous populations in Chile by considering the census processes of 1992 and 2002, the institutional action behind the definition and operation of ethnic records, and ethnographic information. We argue that in both census processes, which were based on self-ascribed concepts of "culture" and "people", respectively, heterogeneous and ever-transforming perceptions and collective identifications are made evident. An interpretation of this issue is drawn from the highly diverse socio-historic shaping of identifications and senses of collective belonging that characterize the indigenous populations in the country. In addition, we consider the sudden changes on conscience and the valuation of cultural difference between both census processes. Equally important is the referential shift from culture to people since, in terms of self-ascription, the later concept is semantically more restrictive than the former. One of the most relevant implications of this analysis lies in the fact that the premise of a direct relationship between ethnic self-ascription and objective biographic basis is only partially fulfilled. Thus, the weakness of official procedures to "count Indians" in Chile is made evident.
\end{abstract}

Key words: National Census - ethnic self-ascription - cultural belonging - collective identification.

Recibido: marzo 2005. Aceptado: agosto 2005.

\section{Introducción}

En los censos nacionales de población y vivienda de 1992 y 2002 se introdujo una pregunta referida a los pueblos indígenas u originarios del país. Revisando los resultados, se advierten diferencias intercensales significativas por su envergadura, las que afectan no sólo a las cuantificaciones para el pueblo mapuche (lo que fue más publicitado), sino que también a los demás pueblos indígenas del país.

Algunas reacciones iniciales de sorpresa o indignación acompañaron los resultados obtenidos de la pregunta $\mathrm{N}^{\circ} 21$ del XVII Censo Nacional de Población y VII de Vivienda de 2002 (INE 2002a 
y b). ${ }^{5}$ Esta pregunta fue una versión modificada de una análoga del Censo de 1992 donde se consultaba por la "pertenencia" a las principales "culturas indígenas" del país (INE 1992). Por parte de intelectuales mapuche (Valdés $2003 \mathrm{Ms}$ ) y académicos ${ }^{6}$ se insinuó la posibilidad de una manipulación de las preguntas censales, muy conveniente al gobierno, ya que la disminución en las cifras era dramática y que ello podría servir como un argumento útil para contener el escalamiento de las demandas indígenas de la última década. Todo el revuelo generado y particularmente la acusación de manipulación de los datos llevaron a una respuesta pública del Director del Instituto Nacional de Estadísticas (INE), en la que defiende la validez de las cifras del Censo de 2002 y reafirma lo ya sostenido por el INE diez años atrás, donde se acepta la existencia de distorsiones. ${ }^{7}$

La tranquilidad se restableció pronto, amparada en la fórmula que en los resultados censales referidos a población indígena de 1992 se introdujeron sesgos por inexperiencia, pero que éstos se habían corregido en el Censo de $2002^{8}$, y que no eran comparables intercensalmente, por lo tanto no cabía nuevos comentarios. Otros, en los movimientos indígenas o cercanos a ellos siguieron y siguen pensando en lo conveniente que para el gobierno resulta una disminución drástica de los indígenas en las cifras censales del país. Como por la época se venían confirmando incrementos en partidas presupuestarias para atender planes y programas dirigidos a los pueblos indígenas del país (en la Corporación Nacional de Desarrollo

5 B. Melín, Presidente Regional de Comunidades Mapuches denominó "censocidio" a la situación en una declaración a un diario metropolitano; otro de la IX Región lo llamó "genocidio burocrático" (Bussani 2003).

6 Sendas cartas a El Mercurio, del 20 y 30 de abril de 2003, por parte de S. Donoso, Profesor de Legislación Indígena y Políticas Públicas.

7 Carta a El Mercurio del 24 de abril de 2003 por parte de M. Aguilera, Director Nacional del Instituto Nacional de Estadísticas (INE).

8 El Director del INE: “... habiéndose advertido responsablemente lo anterior (distorsiones en el Censo de 1992 respecto de lo que se quería recoger: la convergencia o concurrencia al unísono de autoadscripción de pertenencia [un acto subjetivo] y base objetiva de la pertenencia cultural) la pregunta sobre etnias en el Censo 2002 fue elaborada en forma más precisa, apuntando a un objetivo único: la pertenencia a la etnia" (Carta a El Mercurio del 24 de abril de 2003).
Indígena (CONADI), en otras inversiones sectoriales, en la implementación del Programa Orígenes), la brutal disminución poblacional detectada no acarreó, como se temía, una disminución de la acción social del Estado hacia los indígenas.

Frente a variaciones intercensales significativas, ¿se puede hablar de "censocidio"?, ¿o de un "genocidio burocrático"?; ¿deberemos conformarnos con considerar los recientes resultados de "contar indígenas" (sensu Lavaud y Lestage 2002) como incomparables, como datos que expresan cuantitativamente realidades muy distintas y por lo tanto inconmensurables? Proponer una interpretación preliminar de los resultados de los Censos de 1992 y 2002 y relacionarlos supone una consideración cuidadosa de varios aspectos. El que aquí nos interesa abordar, es el de las condiciones subjetivas implicadas en la consulta, y la respuesta por pertenencia a cultura y pueblo indígena: ¿en qué consiste en Chile hoy, y ayer, preguntar por pertenencia indígena?; ¿es algo aparentemente simple y sencillo como pudiera ser inquirir a un residente por el material de las paredes de su vivienda?; ¿y es algo también simple y obvio responderlo? Nuestra hipótesis es que, por el contrario, se trata de procesos complejos, lo que requiere, en primer lugar, intentar aclarar cómo y en qué condiciones se pregunta, y desde qué lugar, y desde qué posiciones de sujeto se responde en 1992 y en 2002.

Desarrollaremos dos hipótesis: la primera propone que las nociones de "cultura" y "pueblo" indígenas remiten a entidades diferentes aunque relacionadas en el sentido común de la población nacional encuestada. La de cultura, semánticamente con mayor cobertura de significados, conlleva varios principios o criterios de adscripción posibles de ocupar; en tanto que la de pueblo, semánticamente más restringida, resulta más exigente en cuanto a los criterios de suscripción para pertenencia. De allí se desprende que debiéramos encontrar autoadscripciones más numerosas para cultura que para pueblo y, luego, que estas declaraciones rebasan considerablemente el ámbito de lo que hemos denominado adscripciones originadas en construcciones biográficas verosímiles.

La segunda asunción, que engloba a la primera, señala que la variación intercensal de las declaraciones de pertenencia debe interpretarse, además del cambio de entidad de referencia, por factores 
de contexto. Por una parte, es necesario atender la formación histórica de la conciencia de alteridad e identidad colectivas, con importantes variaciones en los distintos pueblos originarios del país. Por otra, un incremento exponencial de la conciencia étnica ha tenido lugar durante la década de 1990 y años siguientes, en razón de los activos procesos de etnificación y etnogénesis que se llevaron a efecto, lo que conlleva una expansión considerable de las percepciones de identidad/ alteridad étnicas en las poblaciones "indias" o con antecedentes biográficos en esta categoría social, como también, de manera más general, en el conjunto de la población nacional. El resultado tampoco es ajeno a las formas de identidad/alteridad preexistentes a este momento de cierto auge de lo "étnico", en la medida que los actos de adscripción dependen tanto o más de un ambiente que de una historia. La expansión de esa conciencia comporta varios fenómenos asociados: a escala nacional, la segmentación de las valoraciones sobre los pueblos indígenas y la reelaboración de visiones y contravisiones, el incremento de un sentido de pertenencia a pueblo en algunos grupos y las variaciones regionales significativas y dinámicas de diferenciación identitaria intra grupos.

Hemos organizado nuestra exposición según el siguiente orden. Primero haremos una breve reseña de la experiencia histórica de censar indígenas en el país, lo que nos proporcionará un punto de apoyo para situar los intentos más recientes. En segundo lugar, analizaremos los censos o, más bien, las preguntas y respuestas de los censos recientes, junto a algunos elementos de contexto, para de aquí avanzar a una interpretación buscando reconocer claves y criterios. Luego, con base en lo anterior, se propondrá una tipología de modalidades de pertenencia étnica e identificación concurrentes en los censos. Las conclusiones integran de manera razonada las principales adquisiciones alcanzadas. Omitimos aquí la información censal cuantificada, salvo lo indispensable para el desarrollo y justificación de nuestro argumento (en Tablas 1, 2 y 3 ).

\section{Contar indígenas en Chile}

\section{La experiencia histórica}

El registro de indígenas mediante censos de población no es una materia de los últimos años; se trata más bien de un asunto antiguo. ${ }^{9}$ Aun cuando se tenía conocimiento de la existencia de poblaciones indígenas en el país, de su importancia o irrelevancia numérica, de sus cuantías aproximadas, de su peso político militar (en particular, el de los mapuche), no será sino hasta los censos de 1885 y 1895 que la población indígena es considerada censalmente. Lo fue como una categoría de población en un región específica (Araucanía y provincias sureñas) (Pinto 2004 Ms-d y Ms-f). Es en el Censo de 1907 que se logra por primera vez, desde la ocupación militar de la zona, una cuantificación sistemática y resultados confiables sobre el número de indígenas "araucanos". Este censo marca entonces el inicio del tratamiento profesional de las cuantificaciones censales de la población indígena del país. Se trata un esfuerzo circunscrito a los "araucanos" de las provincias de Arauco, Bío Bío, Malleco, Cautín, Valdivia y Llanquihue. Este censo entregó como resultado la existencia de 101.118 indígenas concentrados principalmente en Cautín y Valdivia, el doble de lo que se suponía. Los criterios de identificación por parte de los empadronadores fueron culturales y objetivos: lengua, vestimenta y modo de vida (religión, hábitos y costumbres) (Pinto 2004 Ms-a).

El Censo de Población de 1920 también incluyó un censo especial de indígenas (de "indios araucanos”), donde se registró información sobre varios tópicos (población, sexo, edad, instrucción). Como en el de 1907, lo indígena estaba circunscrito a las "provincias araucanas" (Arauco, Bío Bío, Malleco, Cautín, Valdivia y Llanquihue) (Pinto 2004 Ms-b). El Censo de 1930 da continuidad a los censos especiales logrados con éxito en 1907 y 1920. El de 1940 es de gran interés, pues, aunque nunca se publicó de manera integrada, registró a la población mapuche por comunas y reducciones, agregando el número de viviendas y la población desagregada por género (hombres y mujeres), que en total sumaron 115432 personas (Pinto 2005 Ms).

\footnotetext{
9 Agradecemos la información que sigue al profesor J. Pinto de la Universidad de La Frontera, quien nos facilitara varios trabajos inéditos y ponencias referidos precisamente a los censos nacionales del siglo XX, en los cuales lo indígena es tratado profusamente (Pinto 2004 Ms-a, Ms-b, Ms-c, Ms-d, Ms-e, Ms-f y 2005 Ms).
} 
HANS GUNDERMANN K., JORGE IVAN VERGARA DEL S., ROLF FOERSTER G.

\begin{tabular}{|c|c|c|c|c|c|c|c|c|c|}
\hline \multirow{2}{*}{$\begin{array}{l}\text { División política / } \\
\text { Grupos étnicos }\end{array}$} & \multicolumn{2}{|c|}{ Etnias andinas $\left({ }^{*}\right)$} & \multicolumn{2}{|c|}{ Mapuche } & \multicolumn{2}{|c|}{ Rapanui } & \multicolumn{2}{|c|}{ Etnias fueguinas $(* *)$} & \multirow{2}{*}{$\begin{array}{c}\% \text { de la } \\
\text { población } \\
\text { total en la } \\
\text { unidad } \\
\text { adminis- } \\
\text { trativa }\end{array}$} \\
\hline & $\mathbf{N}^{0}$ & $\begin{array}{c}\% \text { (de la } \\
\text { población } \\
\text { étnica } \\
\text { total) }\end{array}$ & $\mathbf{N}^{o}$ & $\begin{array}{c}\% \text { (de la } \\
\text { población } \\
\text { étnica } \\
\text { total) }\end{array}$ & $\mathbf{N}^{0}$ & $\begin{array}{c}\% \text { (de la } \\
\text { población } \\
\text { étnica } \\
\text { total) }\end{array}$ & $\mathbf{N}^{o}$ & $\begin{array}{c}\% \text { (de la } \\
\text { población } \\
\text { étnica } \\
\text { total) }\end{array}$ & \\
\hline Total país & 48477 & $4.86 \%$ & 928060 & $92.96 \%$ & 21848 & $2.19 \%$ & $\mathbf{s} / \mathbf{i}(*)$ & $\mathbf{0}$ & $10.33 \%$ \\
\hline I Región de Tarapacá & 15461 & $61.06 \%$ & 9557 & $37.74 \%$ & 302 & $1.20 \%$ & $\mathrm{~s} / \mathrm{i}$ & 0 & $10.39 \%$ \\
\hline II Región de Antofagasta & 4164 & $24.03 \%$ & 12053 & $72.46 \%$ & 417 & $2.51 \%$ & $\mathrm{~s} / \mathrm{i}$ & 0 & $5.69 \%$ \\
\hline III Región de Atacama & 1313 & $15.74 \%$ & 6747 & $80.90 \%$ & 280 & $3.36 \%$ & $\mathrm{~s} / \mathrm{i}$ & 0 & $5.14 \%$ \\
\hline IV Región de Coquimbo & 2102 & $10.03 \%$ & 18010 & $85.92 \%$ & 849 & $4.05 \%$ & $s / i$ & 0 & $5.85 \%$ \\
\hline V Región de Valparaíso & 2981 & $4.57 \%$ & 58945 & $90.31 \%$ & 3344 & $5.12 \%$ & $\mathrm{~s} / \mathrm{i}$ & 0 & $6.41 \%$ \\
\hline VI Región B. O’Higgins & 1317 & $3.47 \%$ & 35579 & $93.62 \%$ & 1108 & $2.92 \%$ & $\mathrm{~s} / \mathrm{i}$ & 0 & $7.57 \%$ \\
\hline VII Región del Maule & 1750 & $5.01 \%$ & 32444 & $92.97 \%$ & 705 & $2.02 \%$ & $\mathrm{~s} / \mathrm{i}$ & 0 & $5.82 \%$ \\
\hline VIII Región del Bío Bío & 3903 & $2.98 \%$ & 125180 & $95.65 \%$ & 1791 & $1.37 \%$ & $\mathrm{~s} / \mathrm{i}$ & 0 & $10.54 \%$ \\
\hline IX Región de la Araucanía & 1214 & $0.84 \%$ & 143769 & $98.90 \%$ & 381 & $0.26 \%$ & $\mathrm{~s} / \mathrm{i}$ & 0 & $26.29 \%$ \\
\hline X Región de los Lagos & 1620 & $2.28 \%$ & 68727 & $96.65 \%$ & 759 & $1.07 \%$ & $\mathrm{~s} / \mathrm{i}$ & 0 & $10.46 \%$ \\
\hline XI Región de Aisén & 136 & $3.92 \%$ & 3256 & $93.75 \%$ & 81 & $2.33 \%$ & $\mathrm{~s} / \mathrm{i}$ & 0 & $6.22 \%$ \\
\hline XII Región de Magallanes & 208 & $4.07 \%$ & 4714 & $92.34 \%$ & 183 & $3.58 \%$ & $\mathrm{~s} / \mathrm{i}$ & 0 & $4.82 \%$ \\
\hline Región Metropolitana & 12308 & $2.84 \%$ & 409079 & $94.47 \%$ & 11648 & $2.69 \%$ & $\mathrm{~s} / \mathrm{i}$ & 0 & $11.25 \%$ \\
\hline
\end{tabular}

Tabla 1. Población indígena de 14 años y más según grandes categorías étnicas y divisiones político administrativas en el XVI Censo de Población de 1992. Elaboración a partir de datos del XVI Censo de Población de 1992 (INE 1992). (*) El concepto incluye a la etnia aymara, atacameña, quechua y colla; (**) Considera a kawaskar y yagán.

\begin{tabular}{|c|c|c|c|c|c|c|c|c|c|c|}
\hline \multirow{2}{*}{$\begin{array}{l}\text { División política / } \\
\text { Grupos étnicos }\end{array}$} & \multicolumn{2}{|c|}{ Etnias andinas } & \multicolumn{2}{|c|}{ Mapuche } & \multicolumn{2}{|c|}{ Rapanui } & \multicolumn{2}{|c|}{ Etnias fueguinas } & \multicolumn{2}{|c|}{ Población indígena } \\
\hline & $\begin{array}{l}\text { Población } \\
\text { andina } \\
\text { regional }\end{array}$ & $\begin{array}{c}\% \\
\text { de la } \\
\text { población } \\
\text { andina } \\
\text { regional }\end{array}$ & $\begin{array}{c}\text { Población } \\
\text { mapuche } \\
\text { regional }\end{array}$ & $\begin{array}{c}\% \\
\text { de la } \\
\text { población } \\
\text { étnica } \\
\text { regional }\end{array}$ & $\begin{array}{c}\text { Población } \\
\text { rapanui } \\
\text { regional }\end{array}$ & $\begin{array}{c}\% \\
\text { de la } \\
\text { población } \\
\text { étnica } \\
\text { regional }\end{array}$ & $\begin{array}{c}\text { Población } \\
\text { fueguina } \\
\text { regional }\end{array}$ & $\begin{array}{c}\% \\
\text { de la } \\
\text { población } \\
\text { étnica } \\
\text { regional }\end{array}$ & $\begin{array}{l}\text { Población } \\
\text { indígena }\end{array}$ & $\begin{array}{c}\% \\
\text { de la } \\
\text { población } \\
\text { total }\end{array}$ \\
\hline Total país & 78889 & $11.40 \%$ & 604349 & $87.31 \%$ & 4647 & $0.67 \%$ & 4307 & $0.62 \%$ & 692192 & $4.58 \%$ \\
\hline I Región Tarapacá & 43061 & $88.48 \%$ & 5372 & $11.04 \%$ & 86 & $0.18 \%$ & 146 & $0.30 \%$ & 48665 & $11.46 \%$ \\
\hline II Región Antofagasta & 18543 & $81.30 \%$ & 4117 & $18.05 \%$ & 42 & $0.18 \%$ & 106 & $0.47 \%$ & 22808 & $4.97 \%$ \\
\hline III Región Atacama & 5242 & $70.77 \%$ & 2057 & $27.77 \%$ & 58 & $0.78 \%$ & 50 & $0.68 \%$ & 7407 & $3.01 \%$ \\
\hline IV Región Coquimbo & 1515 & $29.26 \%$ & 3514 & $67.88 \%$ & 63 & $1.22 \%$ & 85 & $1.64 \%$ & 5177 & $0.87 \%$ \\
\hline V Región Valparaíso & 1202 & $6.43 \%$ & 14594 & $78.00 \%$ & 2671 & $14.28 \%$ & 241 & $1.29 \%$ & 18708 & $1.24 \%$ \\
\hline VI Región B. O’Higgins & 306 & $3.07 \%$ & 9485 & $95.25 \%$ & 54 & $0.54 \%$ & 113 & $1.14 \%$ & 9958 & $1.30 \%$ \\
\hline VII Región Maule & 225 & $2.76 \%$ & 7756 & $95.08 \%$ & 47 & $0.58 \%$ & 129 & $1.58 \%$ & 8157 & $0.91 \%$ \\
\hline VIII Región Bío Bío & 555 & $1.03 \%$ & 53104 & $98.20 \%$ & 126 & $0.23 \%$ & 293 & $0,54 \%$ & 54078 & $3.00 \%$ \\
\hline IX Región Araucanía & 699 & $0.34 \%$ & 203221 & $99.52 \%$ & 102 & $0.05 \%$ & 173 & $0.08 \%$ & 204195 & $30.79 \%$ \\
\hline X Región los Lagos & 634 & $0.62 \%$ & 100327 & $98.62 \%$ & 158 & $0.16 \%$ & 614 & $0.60 \%$ & 101733 & $10.55 \%$ \\
\hline XI Región Aisén & 137 & $1.70 \%$ & 7546 & $93.59 \%$ & 27 & $0.33 \%$ & 353 & $4.38 \%$ & 8063 & $9.84 \%$ \\
\hline XII Región Magallanes & 146 & $1.53 \%$ & 8621 & $90.32 \%$ & 25 & $0.27 \%$ & 752 & $7.88 \%$ & 9544 & $6.92 \%$ \\
\hline Región Metropolitana & 5583 & $2.92 \%$ & 182963 & $95.83 \%$ & 1169 & $0.61 \%$ & 1217 & $0.64 \%$ & 190932 & $3.26 \%$ \\
\hline
\end{tabular}

Tabla 2. Población indígena en el país según grandes categorías étnicas en el XVII Censo de Población de 2002. Elaboración con base en datos del XVII Censo de Población de 2002 (INE 2002). 


\begin{tabular}{|c|c|c|c|c|c|c|c|c|c|}
\hline \multirow{2}{*}{$\begin{array}{l}\text { Divisiones administrativas / } \\
\text { autoadscripción }\end{array}$} & \multicolumn{2}{|c|}{ Población total } & \multirow{2}{*}{$\begin{array}{l}\text { Crecimiento } \\
\text { Intercensal }\end{array}$} & \multirow{2}{*}{$\begin{array}{c}\% \text { de } \\
\text { crecimiento } \\
\text { intercensal } \\
\text { (a) }\end{array}$} & \multirow{2}{*}{$\begin{array}{l}\text { Población } \\
\text { indígena } \\
1992 \\
\text { corregida } \\
\text { (b) }\end{array}$} & \multirow{2}{*}{$\begin{array}{c}\text { Población } \\
\text { indígena } \\
1992 \\
\text { corregida y } \\
\text { actualizada } \\
\quad(a+b)\end{array}$} & \multirow{2}{*}{$\begin{array}{c}\text { Población } \\
\text { indígena } \\
2002\end{array}$} & \multirow{2}{*}{$\begin{array}{c}\text { Variación } \\
\text { entre } \\
1992 \\
\text { corregido y } \\
\text { actualizado } \\
\text { respecto } \\
\text { de } 2002\end{array}$} & \multirow{2}{*}{$\begin{array}{l}\text { Variación } \\
\text { porcentual }\end{array}$} \\
\hline & 1992 & 2002 & & & & & & & \\
\hline Total país & 13348401 & 15116435 & 1768034 & $13.25 \%$ & 1274228 & 1443063 & 692192 & -750871 & $-\mathbf{5 2 . 0 3 \%}$ \\
\hline I Región de Tarapacá & 339579 & 424484 & 84905 & $25.00 \%$ & 32478 & $36781\left(^{*}\right)$ & 48665 & 11884 & $32.31 \%$ \\
\hline II Región de Antofagasta & 410724 & 481931 & 71207 & $17.34 \%$ & 21430 & $24269(*)$ & 22808 & -1461 & $-6.02 \%$ \\
\hline III Región de Atacama & 230873 & 253205 & 22332 & $9.67 \%$ & 10815 & 11861 & 7407 & -4454 & $-37.56 \%$ \\
\hline IV Región de Coquimbo & 504387 & 603133 & 98746 & $19.58 \%$ & 27040 & $30623(*)$ & 5177 & -25.446 & $-83.09 \%$ \\
\hline V Región de Valparaíso & 1384336 & 1530841 & 146505 & $10.58 \%$ & 82548 & 91282 & 18708 & -7574 & $-79.51 \%$ \\
\hline VI Región L. B. O’Higgins & 696369 & 775883 & 79514 & $11.42 \%$ & 48617 & 54169 & 9958 & -44211 & $-81.62 \%$ \\
\hline VII Región del Maule & 836141 & 905401 & 69260 & $8.28 \%$ & 44773 & 48480 & 8157 & -40323 & $-83.17 \%$ \\
\hline VIII Región del Bío Bío & 1734305 & 1859546 & 125241 & $7.22 \%$ & 168036 & 180168 & 54078 & -126090 & $-69.98 \%$ \\
\hline IX Región de la Araucanía & 781242 & 867351 & 86109 & $11.02 \%$ & 187861 & 208563 & 204195 & -4368 & $-2.09 \%$ \\
\hline X Región de los Lagos & 948809 & 1066310 & 117501 & $12.38 \%$ & 91250 & 102547 & 101733 & -814 & $-0.79 \%$ \\
\hline XI Región de Aisén & 80501 & 89986 & 9485 & $11.78 \%$ & 4538 & 5073 & 8063 & 2990 & $58.94 \%$ \\
\hline XII Región de Magallanes & 143198 & 147533 & 4335 & $3.03 \%$ & 6430 & 6655 & 9544 & 2889 & $43.41 \%$ \\
\hline Región Metropolitana & 5257937 & 6045192 & 787255 & $14.97 \%$ & 549144 & 631351 & 191362 & -439989 & $-69.69 \%$ \\
\hline
\end{tabular}

Tabla 3. Variación entre el Censo de Población y Vivienda de 1992 (corregido y actualizado) y 2002, para la autoadscripción étnica en la población indígena nacional, según grandes divisiones político administrativas del país. Elaborada con base en datos censales INE (1992 y 2002). (a) Comparando las cifras censales de 1992 y 2002 para la unidad administrativa; (b) La corrección se efectúa aplicando a los resultados regionales y nacionales de indígenas el porcentaje de la población de menos de 14 años de cada región y el país; (*) Se aplicó la tasa de crecimiento intercensal nacional debido a las distorsiones que introducen las fuertes migraciones de población no indígena desde otras regiones que tuvieron lugar en la década de 1990.

De esta manera, desde 1907 en adelante se practicaron registros censales separados para la población mapuche que vivía al sur del Bío Bío. En cuanto a los criterios de identificación, primaron principios objetivos. En el de 1907 fueron culturales (lengua, vestuario, costumbres). En el Censo de 1930 , la cedula dispuesta para los indígenas se aplicó a aquellos que conservaran sus costumbres y vivieran en reducciones al sur del Bío Bío. Los criterios de identificación fueron entonces dos: residencia reduccional y manifestación de prácticas que pudieran ser asociadas a costumbres y modo de vida indígena (Pinto 2004 Ms-c).

El censo de 1952 también consigna información sobre indígenas. La población "araucana" llega a 130747 personas, distribuidas mayoritariamente en Malleco, Cautín y Valdivia. Se destaca entonces el peso regional de su población y su crecimiento respecto de censos anteriores (el de 1930 consignó 98703 personas). ${ }^{10}$ En cuanto a la cobertura

10 Esta última cifra corresponde a población indígena reduccional. Marca un punto de inflexión a la baja respecto de del censo, por primera vez se hace nacional. La acción de "contar indígenas" deja de ser un asunto de interés regional y ahora se hace extensivo a todo el país, pero limitado a los mapuche. Por otra parte, como criterio de identificación se ocupa el de vivienda (vida en reducciones mapuche), agregándose uno de tipo subjetivo: aquellos que declaran ser "araucanos". Se da inicio así al uso de un principio de autoadscripción para definir la pertenencia a la condición sociocultural de indígena (Pinto 2004 Ms-d).

En cuanto a los censos ulteriores, no se habrían realizado empadronamientos especiales para los grupos indígenas del país y tampoco para los mapuche. Incluyen, no obstante, el concepto de reducción dentro de las categorías de unidades pobladas. De acuerdo a lo anterior y dadas las posibilidades de tratamiento estadístico de los datos censales es que, por ejemplo, en el Censo de 1982 pudo realizarse una caracterización de

los resultados censales de 1907 (101118 individuos indígenas) y 1920 (105162 "araucanos"). 
indígenas sobre la base de la residencia, aunque todavía circunscrita a los mapuche reduccionales (Oyarce et al. 1989).

En resumen, los censos indígenas mencionados poseen un carácter regional: su cobertura es de Bío Bío al sur, hasta Chiloé, incluyendo varias situaciones de asentamiento, unidades subregionales y tradiciones culturales indígenas (hoy genéricamente reconocidas como "mapuche", "pehuenche", "huilliche", "lafkenche", entre otras). En su aplicación a los indígenas, se organizan como empadronamientos especiales. Además, son exclusivos, ya que se dirigen sólo a mapuche o "araucanos". Los criterios de identificación, por último, son decididamente objetivos: se concentran en la residencia y el ejercicio de prácticas sociales y culturales distinguibles como indígenas: vestimenta, lengua, modo de vida. Una excepción la hace el de 1952 que ocupa una fórmula mixta: factores subjetivos y objetivos.

No obstante la presencia de algunas cifras censales oficiales de indígenas durante buena parte del siglo XX, al menos en dos campos institucionales también se verificó la necesidad de alcanzar cuantificaciones de población indígena. Estos son el de la ciencia y el de la administración sectorial del Estado; para ser más precisos, de las ciencias sociales y la antropología, y de aquellas reparticiones públicas que aproximadamente desde mediados de siglo, tienen por mandato atender algunos problemas de los pueblos indígenas del país. ${ }^{11}$ En el campo antropológico y de las ciencias sociales puede citarse a Brand (1941), Jara (1956), y Jeannot (1972). En el del Estado, los cálculos de la Dirección de Asuntos Indígenas (DASIN) y su sucesora, el Instituto de Desarrollo Indígena (IDI). Tales conteos y estimaciones podían ser paralelos e incluso contradictorios con resultados censales; otras veces se apoyaban en ellos y los corregían.

La información que progresivamente fue reuniendo la antropología, proporcionando descripciones, configurando tipificaciones, relevando dimensiones caracterizadoras, es retomada luego por algunas reparticiones públicas. Es el caso de la Dirección de Asuntos Indígenas (DASIN) dependiente del Ministerio de Tierras y Colonización desde

11 Se trata de las modernas instituciones mediadoras de la relación entre el Estado y los pueblos indígenas.
1953 en adelante, o el Instituto de Desarrollo Indígena desde $1972^{12}$; a veces también por el Ministerio de Relaciones Exteriores para dar respuesta a compromisos y participación en foros internacionales como los que propiciaba el Instituto Indigenista Interamericano con sus congresos periódicos (Colompil $1972 \mathrm{Ms}$ ). Otras veces esa información era obtenida y elaborada independientemente, en particular por parte de DASIN, que en la década de 1960 realizó un importante esfuerzo de recopilación de información sobre los mapuche en el centro sur del país. ${ }^{13}$

Por lo demás, en la década de 1960 se tiene ya una identificación razonablemente precisa de las áreas indígenas del país y una aproximación a los contingentes de población que en ellos se encontraban presentes. De todos modos, persistían muchas lagunas de información, al punto que en 1972, en su discurso presidencial, Salvador Allende identifica cinco agrupaciones territoriales: "Norte Grande"; "algunos sectores de las Provincias de Coquimbo y Atacama"; Isla de Pascua, "zona de la Araucanía...desde las provincias de Llanquihue, de la isla de Chiloé" y, finalmente, "algunas familias en la zona de los Canales". Agrega que se puede estimar en 800000 el número de indígenas del país, de los cuales sólo la mitad serían mapuche (Allende 1972: 317), lo que constituye una clara sobreestimación de los grupos indígenas no-mapuche.

Esos son los antecedentes de los esfuerzos censales y no censales de cuantificación indígena del último siglo. Lo que sigue después arranca en 1989, cuando la Comisión Técnica de los Pueblos Indígenas y luego el Consejo Nacional de Pueblos Indígenas de Chile ${ }^{14}$ plantearon la nece-

12 En la década de 1960, la Dirección de Asuntos Indígenas tenía entre sus objetivos de trabajo mantener información detallada y actualizada de la población mapuche reduccional, para lo cual implementa una extensa encuesta socioeconómica y demográfica que, según la información disponible, nunca se concluyó.

13 Valdés (1998: Nota 2), citando a Moltedo y otras fuentes consigna diversas estimaciones de población mapuche que se han sucedido entre 1952 y 1990

14 Referentes de organizaciones indígenas del país durante la transición desde el gobierno autoritario al primero de la Concertación de Partidos por la Democracia, y en momentos inmediatamente previos a la formación de la Comisión Especial de Pueblos Indígenas (CEPI) en 1990. 
sidad de salir del marco restringido, en cuanto a sus criterios y cobertura, en que hasta ese entonces se había manejado el conteo de indígenas del país (Cayún 1991). La demanda fue retomada por la Comisión Especial de los Pueblos Indígenas (CEPI) y en paralelo por el Instituto Nacional de Estadísticas (INE), que introdujo una pregunta en el Censo de 1992. Todo ello ocurría en el favorable ambiente generado por el proceso de retorno a la democracia que iniciaba su implementación. Es preciso decir que el INE no sólo recoge una presión nacional, sino que también reacciona ante una tendencia continental de responder a la demanda de información censal de indígenas promovida por los movimientos indios de América Latina y retomada por los distintos gobiernos de la zona. ${ }^{15}$

\section{Las preguntas censales}

\section{El Censo de 1992}

Es en el Censo de 1992 que para "contar indígenas" a lo largo del país se introduce de manera decidida y exclusiva un criterio subjetivo de identificación a través de la pregunta sobre la pertenencia a culturas indígenas. En el Censo de 1952 se optó también por un principio de este tipo, pero complementario a uno objetivo (residencial). Por otra parte, no es una innovación aislada. Se consideró también incluir otra referida a religión y discapacidad. Esta apertura hacia la consideración de un mayor número de categorías sociales originadas en principios de segmentación y división social (género, edad, residencia, y ahora etnia y religión) es consonante con el proceso general de democratización del país y, como un aspecto de lo anterior, con la necesidad de dar visibilidad a grupos y categorías sociales para los cuales, a su vez, se considera que requieren de políticas y cursos de acción estatal específicos. La inclusión en el Censo Nacional de una pregunta por pertenencia a una cultura indígena resulta entonces de un doble requerimiento: reconocimiento con el obje-

15 "Existe una fuerte demanda por investigar el origen étnico de las personas, en particular de los pueblos indígenas. Esta demanda proviene principalmente de los propios indígenas, debido a que requieren información de apoyo a sus planes reivindicativos, y por el sector gubernamental que considera que este es un grupo vulnerable cuyas necesidades deben ser atendidas, considerando su especificidad cultural" (Chackiel 1999: 25). to de disminuir la minorización e invisibilización como grupos sociales (en este caso a través de las cifras oficiales nacionales); y dimensionar y validar la política pública dirigida a los pueblos indígenas del país.

En el XVI Censo de Población de 1992, la pregunta $\left(n^{\circ} 16\right)$ fue la siguiente:

Si es Ud. chileno, ¿se considera perteneciente a alguna de las siguientes culturas?

1. Mapuche

2. Aymara

3. Rapanui

4. Ninguna de las anteriores

Anotemos, primero, que la pregunta censal es antecedida por una cláusula referida a la condición de "chileno", o sea, por una parte, se excluye como respondente de esta pregunta a los extranjeros. A la vez, lo que puede parecer un criterio técnico censal delimita previamente el campo semántico que pretende explicar. $\mathrm{O}$ sea, al anteponer la condición de chileno, tiende de algún modo a colocar como primer referente identitario y obliga al respondente que se considera a la vez indígena a adicionar su identidad étnica a la primera. Esto podría excluir a aquellos indígenas que desestiman o bien consideran secundaria su pertenencia nacional frente a su pertenencia étnica. Sin embargo, es posible suponer que, por el contrario, la pregunta cumplió la función de estimular a chilenos noindígenas para adicionar a su nacionalidad la pertenencia a un grupo étnico.

Segundo, se introduce la opción "ninguna de los anteriores" lo que, aparentemente, deja a una gran mayoría de personas en estado de omisión cultural.

Tercero, aparecen sólo tres pueblos indígenas, lo que representa un vacío para quienes forman parte de otros pueblos originarios, que se invisibilizan, puesto que la opción 4 es vacía, o quedan, teóricamente, obligados a incluirse en otra categoría étnica.

Cuarto, lo más significativo es que se introduce la noción de cultura, desestimando la de pueblo, propuesta por el Consejo Nacional de Pueblos 
Indígenas en 1991 y utilizada ampliamente por las organizaciones y líderes indígenas (CNPI 1991; Cayún 1991: 59).

Finalmente, se establece la noción de pertenencia que, en esta materia, ha continuado sin mayores alteraciones a través de todas las formulaciones de pregunta censal.

\section{La encuesta CASEN de 1996}

La encuesta de caracterización socioeconómica CASEN $^{16}$ de 1996 incluyó una pregunta por pertenencia étnica. Esta sí toma la noción de pueblo, algo apreciado como positivo por todos. La pregunta fue la siguiente:

En Chile la ley reconoce la existencia de ocho pueblos originarios o indígenas ipertenece Ud. a alguno de ellos?

1. Sí, aymara

2. Sí, rapanui

3. Sí, quechua

4. Sí, mapuche

5. Sí, atacameño

6. Sí, coya

7. Sí, kawaskar

8. Sí, yagán

0 . No pertenece a ninguno de ellos

Algo que rápidamente destacó de este estudio fueron las notables diferencias con los resultados obtenidos en el Censo de 1992. Para 1996, la población indígena nacional de todas las edades estimada por la encuesta CASEN correspondió a aproximadamente la mitad de la población de 14 años y más consignada por el Censo de 1992. Si mediante la encuesta se estimó esa población en 635372 individuos, correspondiendo a un $4.5 \%$ de la población nacional (Valenzuela 2002 Ms), unos años antes el Censo contabilizó 998385 individuos de 14 años y más, correspondiendo a un $10.33 \%$ de la población nacional en esos tramos de edad (INE 1992).

16 Encuesta de caracterización socioeconómica que administra el Ministerio de Planificación (MIDEPLAN) como instrumento de ayuda a la definición, focalización y evaluación de políticas sociales.
La encuesta CASEN de 2000

Diferencias análogas volvieron a presentarse en la Encuesta CASEN de 2000, donde la población indígena del país se estimó en 666319 individuos, correspondiendo a un $4.4 \%$ de la población nacional proyectada (Valenzuela $2002 \mathrm{Ms}$ ). En ambos casos se trata, sin embargo, de una proyección a partir de una muestra, dado que la CASEN se aplica a un número aproximado de 68 mil hogares seleccionados en todo Chile. No obstante ello, las diferencias en los resultados advirtieron de la necesidad de una revisión y discusión sobre criterios y preguntas censales más apropiadas. CONADI encargó un estudio al Instituto de Estudios Indígenas de la Universidad de la Frontera, donde se entregan una serie de sugerencias y se proponen algunas alternativas (Pérez y Oyarce $2001 \mathrm{Ms}) .{ }^{17}$

Los criterios recomendados fueron en general los mismos contenidos en la formulación de la nueva pregunta censal por parte del INE en 2002: autoidentificación (y no evaluación objetiva), concepto de pueblo (y no de cultura), listado de etnias más amplio (y no sólo tres), aplicación universal (no sólo a los de 14 y más años), sin cláusula introductoria (que pudiera generar inducciones), pregunta cerrada (y no abierta), pero desechando la inclusión de preguntas complementarias o subordinadas (seguramente por su costo). La pregunta del Censo de Población y Vivienda de 2002 fue, en definitiva, la siguiente:

¿Pertenece usted a alguno de los siguientes pueblos originarios o indígenas?

1. Alacalufe (kawashkar)

2. Atacameño

3. Aymara

4. Coya

5. Mapuche

6. Quechua

7. Rapanui

8. Yámana (Yagán)

0 . Ninguno de los anteriores

17 Estos y otros autores vienen desde la década de 1990 realizando estudios y análisis sociodemográficos de la población mapuche. Entre otros trabajos se cuentan el de Espina y colaboradores (1998) y el de UFRO, INE, PAESMI, CELADE (1990). 


\section{Sentido de pertenencia a cultura y pueblo}

Con ocasión del Censo Nacional de 1992, el reconocimiento de los pueblos indígenas constituía algo aún en discusión, hasta que el proyecto de ley presentado fuera debatido y aprobado, lo que ocurrió en octubre de 1993. Los pueblos indígenas $\mathrm{u}$ originarios con presencia en los espacios abiertos por la Concertación de Partidos por la Democracia eran los mapuche, aymara y rapanui, en ese orden de presencia. Los atacameños recién estaban mostrándose y, para efectos prácticos, las etnias fueguinas y las demás andinas (quechuas y collas), existían sólo en el papel. Tendrán existencia oficial más tarde, con la Ley Indígena. Se trató de un censo con pocos pueblos indígenas invitados, dado el estado en que se encontraba el proceso de reconocimiento y de etnificación, en pleno desarrollo por ese entonces.

¿Qué tienen de común y de diferente las ideas de pertenencia a una cultura y pertenencia a un pueblo? Sostendremos que las nociones de "cultura" y "pueblo" son en el sentido común de la población de nuestro país, indígenas y no indígenas, conceptos relacionados. Si se pertenece a un pueblo es esperable que se tenga la cultura de ese pueblo. Si se tiene una cierta cultura, entonces es esperable que además se pertenezca a un determinado pueblo, el que corresponde a esa cultura. Sin embargo, se puede participar de una cultura en grados variables sin que se pertenezca o se crea pertenecer a un pueblo que guarda correspondencia con esa cultura. Por ejemplo, los aymaras modernos del norte de Chile no tenían una noción de pertenencia a "pueblo aymara" sino hasta los procesos de etnificación y etnogénesis recientes, aun cuando eran plenamente partícipes de una cultura indígena andina, y a través de la noción de "costumbre" (prácticas locales tradicionales) tenían una conciencia bastante definida de ello (Gundermann 2003).

En procesos de circulación étnica, muy activos en Latinoamérica, objetivamente se puede mantener prácticas y significados otorgados a muchas cosas con antecedentes culturales indígenas, pero con sentidos de pertenencia a otros grupos y categorías sociales. La relación recíproca también es verdadera: llegado el caso se puede ser partícipe de un pueblo, considerarse así, con muy poca unidad cultural respecto de otros sujetos del mismo. Reparemos, por ejemplo, en los numerosos indígenas de extracción urbana que en el contexto de procesos de etnificación y etnogénesis se han "reencontrado con las raíces", han "despertado" culturalmente.

Convengamos también que, a mayor visibilidad pública, presencia política y legitimidad social de un pueblo o grupo social dado, quienes plausiblemente consideran poseer algún componente de cultura proveniente de aquel, mayor disposición tendrán para señalar una pertenencia a esa cultura y en un cierto número de casos, a pertenecer también a ese grupo o pueblo. Durante la década transcurrida entre ambos censos se ha avanzado claramente en esta dirección, aunque también han surgido discursos que introducen estereotipos aparentemente nuevos, pero que tienen importantes precedentes históricos, como los de "radicalismo étnico, "rebelión étnica", "grupos extremistas" o "autonomismo", aplicados al movimiento mapuche que han protagonizado los conflictos con empresas forestales. ${ }^{18}$ Se aceptará, asimismo, que lo que resulta plausible (una nutrida biografía de referencias vinculantes con un grupo sociocultural particular) puede tener por puntos de relación cosas muy disímiles. Hacemos notar que hasta aquí no estamos incluyendo a la pura declaración de pertenencia por solidaridad externa, que también se ha hecho presente en los censos (Gundermann et al. 2004 Ms-a y Ms-b).

La pertenencia a un pueblo considera un aspecto del que carece la pertenencia a una cultura. Supone una percepción suficientemente definida de integrar una comunidad sociológica e histórica amplia, con vigencia en el presente. Para un cierto número de sus miembros, pero no para todos, implica también una experiencia y voluntad de pertenencia y, con ello, su adscripción a una comunidad de futuro, de proyecto. Hablamos de comunidad no en el sentido antropológico, como una unidad social basada en relaciones de copresencia sino, en la perspectiva de Anderson (1981), en una entidad abstracta e impersonal formada imaginariamente por lazos étnicos. Por una cultura, en cambio, debe entenderse un conjunto diversificado de prácticas y significados vinculados a ellas, características de un grupo humano (una etnia, un pueblo, una nación), aun cuando

18 Ver Vergara y colaboradores (1999: 113-119) y Foerster y Vergara (2003: 146-155). 
en principio no necesariamente exclusivas a él. Esto último dependerá más bien de la configuración de fronteras sociales del grupo existente. ${ }^{19}$ En las condiciones modernas cada vez más se pierde esta exclusividad. La cultura ha dejado de tener por exclusiva fijación un grupo humano específico e incluso una geografía convencional; fragmentos, partes y piezas suelen ser más ampliamente compartidos (Hannerz 1992 y 1998). Los pueblos indígenas no escapan a esto.

Muchos pueden sentir que participan de una cultura indígena, por tenue que este compartir sea en la práctica. Bastará con que se identifique con algunos símbolos o emblemas caracterizadores, lo que puede entonces darse de manera muy variada. De allí a suscribir una pertenencia hay un paso. Por el contrario, no es posible pertenecer a un pueblo de esa forma. Esto último es más restrictivo; exige un vínculo biográfico o su postulado al menos. La pertenencia a un pueblo tiene entonces algo de condición dada, de un estatus prescriptivo, del modo como se heredan/reciben los lazos de sangre (de hecho, el código preferido de las retóricas de pueblo es, precisamente, el de la sangre, los antepasados, los agravios inflingidos a ellos que se deben reparar, entre otros) (Calhoun 1997). No es que la noción de cultura cuya pista aquí seguimos carezca de relación con esas retóricas de pueblo. Recuérdese, para el caso mapuche, la cerrada relación que se establece entre "pueblo" y "admapu" (la costumbre, lo que le da fisonomía cultural al pueblo). En lo que insistimos es que en la forma que socialmente se razona la relación de los individuos con una cultura, no resulta de ello una exclusividad, así como tampoco acuerda necesariamente pertenencia a un pueblo. Por eso es que, tendencialmente, una respuesta por pertenencia a una cultura indígena arrastrará consistentemente más casos afirmativos que una por pertenencia a un pueblo. La comparación de los resultados avala estas aseveraciones (Gundermann et al. 2004 Ms-a y Ms-b). ${ }^{20}$

19 Reconociendo la gran cantidad de literatura sobre el tema, la mención obligada es Barth (1969). En esta misma línea, es útil el manual de Eriksen (1993).

20 De esta manera, creemos útil comparar los resultados censales, no porque correspondan a lo mismo, sino precisamente porque se refieren a cosas distintas. La variación de las respuestas sobre pertenencia (base de comparación) a cultura y a pueblo nos enseña acerca de las identificaciones e identidades de la población indígena y también de
El esquema analítico previo vincula pertenencia a "cultura" y "pueblo". Para su utilización con fines de análisis censal se requiere que los respondentes entiendan a lo menos la significación de base de ambos vocablos y su conexión. ¿Qué tanto esto es así en el caso de los pueblos indígenas? Para el censo del 2002 no nos cabe duda que, de manera muy extendida, existía entre la población indígena del país una comprensión básica cabal de ambos términos y su relación. En la década transcurrida entre los dos censos las nociones de "minoría étnica", "población aborigen", "pueblos originarios", "culturas indígenas", "minoría cultural", "pueblo indígena", fueron extensivamente divulgadas.

Creemos que, en el censo de 2002, la población indígena nacional entendió lo que se le preguntaba. ¿Ocurrió lo mismo en el censo de 1992? Aparentemente no, pero ¿en qué medida? No lo sabemos con precisión, aunque podemos consignar algunos elementos de juicio. Primero, por aquel entonces había un segmento de población indígena plenamente interiorizado de los significados actuales del vocablo cultura (en el sentido antropológico, ya indicado). Segundo, este conocimiento se encontraba más extendido en algunas regiones que en otras. Tal parece que en la zona mapuche era mucho mejor conocido que en la aymara. Tercero, por los medios de comunicación del país, en relación con los 500 años del inicio de la colonización europea de América, se habían empezado a manejar acepciones de cultura en el sentido de "cultura de un pueblo". Más ampliamente todavía, los medios de comunicación venían divulgando una valoración por las diferencias individuales y culturales. Cuarto, los encuestadores tenían una instrucción básica de cuál era el sentido de la pregunta censal, por lo que podemos suponer que, en muchos casos, ayudaron a resolver confusiones y a aclarar en qué sentido es que se preguntaba. Y quinto, si hubiera un desconocimiento importante del significado de cultura en la pregunta censal, deberíamos esperar que a mayor aislamiento geográfico (y comunicativo, hasta cierto punto) hubiera una

alguna no indígena respecto de aquella. Dependiendo de cómo se presente esta variación, obtendremos evidencia favorable a la interpretación que seguimos o bien nos veremos forzados a replantearla (Tabla 3 ). 
importante subdeclaración. No parece ser este el caso si nos atenemos a los resultados aymaras, donde las comunas más alejadas, en plena cordillera andina (General Lagos y Colchane), tuvieron en 1992 altos porcentajes de declaración de pertenencia cultural. En suma, podemos sostener que el conocimiento y comprensión del concepto de cultura en 1992 fue menos generalizado que el de pueblo en 2002, diferencia que no puede entenderse como sinónimo de un bajo o sólo mediano entendimiento de aquel y tampoco atribuir a ello, sin más, autoadscripciones inferiores a las esperadas para un grupo o lugar. Por lo demás, como aquí sostendremos, una interpretación de la autoadscripción étnica indígena en los censos nacionales supone acudir a más fundamentos que simplemente una cuestión de información.

\section{Condiciones de aplicación y recepción de la pregunta por pertenencia a pueblo indígena en el Censo de Población de 2002}

Nos interesa aquí tratar dos aspectos: las condiciones de emisión de la pregunta por pertenencia étnica y, luego, las condiciones de recepción y respuesta ante la pregunta. A continuación se entregan antecedentes acerca del ambiente y la sensibilidad sobre los pueblos indígenas en el período intercensal.

\section{Condiciones de emisión}

Este es un aspecto no problematizado de la pregunta sobre la pertenencia indígena, aunque metodológicamente resulta de gran importancia. Se trata de un asunto relevante de todo estudio basado en encuestas. Es imprescindible que la pregunta sea unívoca y que los encargados de plantearla y de registrar respuestas en las cédulas especialmente preparadas para ello tengan el adiestramiento suficiente para garantizar esa univocidad. Por desgracia, no disponemos de información extensiva acerca de la convergencia y la variación de la emisión de las preguntas censales, y en particular de aquella que considera a los indígenas.

Al respecto nos parece de interés la experiencia vivida por uno de los autores de este trabajo al ser encuestado en el Censo de abril de 2002. El caso en cuestión goza de la ventaja de hacer pre- sente algunas de las complejidades implicadas en el preguntar por formas de pertenencia social como la de cultura o pueblo. El 24 de abril, día del Censo, a eso de la 17.00 horas, se presentó una encuestadora asignada al sector (un ayllu vecino al pueblo de San Pedro de Atacama). Se trataba de una joven profesora aymara, oriunda de Arica. Le tocó cubrir San Pedro de Atacama, donde había un déficit de personal para realizar el Censo. A los presentes nos causó curiosidad su situación y le preguntamos por su trabajo del día. Señaló que había comenzado a trabajar desde muy temprano, tenía sed, casi no había comido y estaba bastante agotada. El sector en que nos había localizado representaba el último a cubrir por ella. Al momento de las preguntas y el registro en la cédula censal, la pregunta ${ }^{\circ} 21$ sobre la pertenencia indígena la formuló en términos de "con cuál cultura indígena nacional nos sentíamos identificados", pasando a continuación a leer las distintas posibilidades existentes (las categorías étnicas consideradas ordenadas alfabéticamente, además de la alternativa de no pertenencia). Le observamos que eso no era lo que específicamente se preguntaba en el Censo, explicándole que conocíamos el formulario y la cartilla de instructivos, debido a que uno de nosotros había participado de una reunión de capacitación. Aceptando la observación, se disculpó atribuyendo el desvío al cansancio del día. La distorsión en la pregunta podría entonces entenderse como el producto de una larga jornada de trabajo. En reemplazo de la explicación previa podría argüirse que, dada la viva conciencia de su condición aymara, manifestada en el curso del diálogo emprendido, la censista empleó concientemente, y quizá no sólo en nuestro caso, la noción de identificación y la de cultura.

La Guía del Censista no entrega ninguna aclaración especial respecto de la pregunta $\mathrm{n}^{\circ} 21$. Los encuestadores debían operar con base en las instrucciones recibidas en la reunión de capacitación previa, pero nos parece indudable que también lo hacen guiándose por etiquetas étnicas entendidas como criterios de racialización (Miles 1989). Es decir, según un repertorio de categorías, conceptos y definiciones portadoras de determinadas atribuciones esenciales, con arreglo a los cuales las personas realizan clasificaciones sociales. Seguramente con variantes, este repertorio forma parte de la cultura de los distintos sectores sociales del país. 
Algunos detalles sobre una capacitación de encuestadores realizada en la ciudad de Iquique semanas antes del XVII Censo de Población, en abril de 2002, ilustran bien el punto. La instrucción referente a la pregunta $\mathrm{n}^{\circ} 21$ fue la de un estricto apego a la autoadscripción, ejemplificándose el criterio de demarcación de la siguiente manera: "Si ud. ve a una persona de tez blanca y a la pregunta sobre pertenencia le responde 'aymara', usted le anota en la cédula censal como aymara. Se debe respetar la declaración de la persona" ${ }^{21}$ Nótese desde ya que los capacitadores (o ese capacitador por lo menos) requiere hacer ostensible el que no se debe atender a los atributos físicos de las personas para efectuar una asignación étnica, sino que solamente a su declaración de pertenencia. ¿Por qué esta insistencia en recalcar el no uso de un criterio subjetivo de clasificación socioétnica por parte del entrevistador? Desde luego, porque no se deben imputar respuestas, sino que estas debe darlas el entrevistado. Pero, además, creemos que se percibe la muy extendida presencia de criterios culturales en los propios encuestadores (profesores, estudiantes universitarios, profesionales), que inadvertidamente pueden ponerlos en acción, porque jes "natural" que uno de tez oscura en Arica.... sea aymara! Es decir, porque está latente la posibilidad de que en las entrevistas censales se actúe de acuerdo a un sistema de clasificaciones sociales generales, dentro del cual, entre otros criterios, se realizan asignaciones basadas en rasgos físicos (color de la piel, rasgos faciales) y sociológicos (apellidos, lugar de nacimiento) para la condición sociocultural de indígena, sin respetar la opción tomada por el consultado. Este sistema de referencias y claves para la clasificación social no se limita, como es de suponer, a las inscripciones étnicas; interviene también en las asignaciones de clase, regionales, raciales, de categorías de edad, de género o socioprofesionales.

Las reacciones que sobre el tema se escucharon en la mencionada reunión fueron del mayor interés. Uno de los que actuaría como censista señaló con cierta displicencia: "Si Ud. la ve blanca como

21 Debemos estos antecedentes a L. Vergara, quien gentilmente nos permitió hacer uso de algunas notas tomadas durante la reunión. la harina [reaccionando al ejemplo dado por el capacitador] y le dice aymara, entonces le pongo aymara, pero si es oscuro y dice no aymara, entonces le pongo aymara", lo que acarreó una nueva aclaración del funcionario del Instituto Nacional de Estadísticas. Como puede advertirse, se estipula aquí un criterio de clasificación mixto, pero alejado de un estricto apego al principio censal de autoadscripción. Un tercero, yendo más lejos, dijo en un tono provocativo: "Yo me salto esa pregunta y si la veo (a la persona) con cara de aymara, entonces le pongo aymara". Este segundo criterio vuelve definitivamente al uso de las representaciones sociales empleadas para efectuar las clasificaciones colectivas en juego en nuestro país. Aplicada, puede ser en algunos casos ser favorable al conteo indígena, pero en otros se rechazará autoadscripción por no correspondencia con marcadores físicos, sociológicos o residenciales de lo indígena y, en el peor de los casos, la respuesta no será otra cosa que un arbitrio del censista.

Lo que nos hemos propuesto destacar es que, ante preguntas como las del censo, se ponen en acción resistencias por conflicto de criterios de asignación a categorías étnicas o, más precisamente, de "pueblos originarios" o "indígenas". Parece suceder que entran en colisión, con más frecuencia de la deseada, criterios de clasificación propuestos por el INE y criterios culturales de clasificación social, verdaderos principios de inteligibilidad de las divisiones sociales y, con ello, de valoración y acción de acuerdo a los cuales tiende a organizarse la interacción social entre los individuos así clasificados. En términos más abstractos, las preguntas a partir de las cuales se pretende estimar la cuantía de la población indígena, parten de determinados supuestos a priori necesarios para la acción estatal de clasificación y ordenamiento social. ${ }^{22}$ Conforman condiciones de inteligibilidad de la propia gestión del Estado; sobre todo, satisfacen los rasgos de universalidad y comparabilidad de los resultados.

22 La idea de "a priori" sociales, aunque referida aquí sólo a la acción estatal, ha sido tomada de Simmel (1977 [1908]: 37-56). Un análisis similar respecto a la definición estatal de pobreza puede verse en Martínez y Palacios (1996: 11-24) 
Debemos también asumir que entran en juego tanto elementos generales con alcance nacional como regionales. Las reacciones observadas en la reunión de Iquique deben, según esto, estar teñidas de matices regionales sobre un fondo cultural común. Dudamos que la capacitación haya sido suficiente como para bloquear estas "contaminaciones" originadas en la acción de criterios de clasificación social extracensales y, eventualmente, en tomas de posición más o menos conscientes sobre lo que "corresponde hacer" en el Censo.

\section{Condiciones de recepción y respuesta}

Nuestra encuestadora bien podría haber incurrido en una asimilación inadvertida entre identificación / pertenencia y cultura / pueblo indígena o aborigen. Ello sería producto de la naturaleza ambigua, a veces paradojal, y en cualquier caso problemática, de las pertenencias étnicas en un contexto sociohistórico como el chileno.

Una declaración de pertenencia a una colectividad o categoría humana supone, por lo general, alguna forma y grado de identificación. Conlleva una comunión de algún tipo entre quien se identifica y lo que sirve de objeto de la identificación. Ambos conceptos se nos presentan así relacionados: la identificación constituye un atributo posible de la pertenencia. Pero lo ya indicado no agota las remisiones de sentido implicadas. Quisiéramos llamar la atención a que la noción de pertenencia presupone una base o sustrato objetivo, o por lo menos su postulado. Demanda que la pertenencia esté fundada en antecedentes biográficos o de otro tipo, o al menos la presunción cierta de ello, que avalen el vínculo. Y una pertenencia fundada debiera acompañarse de adhesión y compromiso; o sea de componentes emocionales, intelectuales y valóricos que nutran la identificación. El que así no ocurra es otra materia pero, en abstracto y fuera de consideraciones particulares, una pertenencia social lleva consigo un imperativo ético de identificación, una lealtad hacia una cierta comunidad, aunque al mismo tiempo, dicha lealtad coexista con otros niveles de identificación (p.e., la etnicidad coexiste con la identificación nacional o de género, entre otros). De esta manera, resulta común la permutación de términos, usualmente inadvertida, para nombrar las vinculaciones de una persona con una cultura o pueblo indígena u originario. La ambigüedad usualmente no llegaría a molestar.
Con estas especificaciones se puede entender mejor la intervención de nuestra entrevistadora y se hace más comprensible la respuesta que aun hoy se obtiene cuando se pregunta por lo que una persona recuerda en materia de indígenas del Censo de 1992, entre ellos varios colegas. Esta misma asimilación conceptual se deslizó en el análisis preliminar realizado por CONADI de las cifras nacionales acerca de los pueblos indígenas obtenidas en el Censo de 2002 (Alcamán 2003 Ms: 4). Por lo general, rememoran que se preguntó por identificación con una cultura. Como ya sabemos, lo que se consultó fue otra cosa: pertenencia a una cultura; en tanto en el censo siguiente fue pertenencia a un pueblo. Una respuesta posible a esta intercambiabilidad de los términos radica entonces en la asociación que se hace entre pertenencia e identificación.

Una pertenencia puede ser una realidad dada para un individuo o un grupo, no buscada, incluso no deseada ni querida. Si una pertenencia está asumida subjetivamente como estigma o es objetivamente lesiva a las posibilidades de desempeño social de los individuos y se hace conciencia de ello, entonces no resulta obvio que a esa o a esas pertenencias acompañen una voluntad de adhesión o, de modo más genérico, una identificación. En los términos indicados, hay pertenencia pero no identificación. Puede haber también una pertenencia objetiva, pero no conocida, o cuando menos no procesada por los sujetos; en ese caso no puede haber identificación. Además de las disociaciones anotadas, es bueno destacar la labilidad de las identificaciones. Por radicar ante todo en el campo de la subjetividad, las identificaciones son dinámicas, están sujetas a cambios, acoplándose a pertenencia o bien operar autónomamente sin ella. Y no pocas veces lo hacen dinámicamente (Gundermann et al. 2004 Ms-a y Ms-b).

Dicho lo anterior, podemos sostener que el de las pertenencias colectivas y la identificación étnica es un terreno diferente que, por ejemplo, el de preguntar por la edad. Esta tiene su escala de medición en años, meses, décadas, sólidamente establecida y reproducida cotidianamente. Preguntar por la pertenencia étnica es bastante distinto entonces que consultar por si se tiene o no un electrodoméstico en el hogar o si se posee o no teléfono móvil. Una categoría como la de edad no es menos subjetiva que la de pertenencia 
étnica; se trata sólo de que una ha tenido un tipo de normalización que la instituye en la conciencia como algo natural, estable, sólido, determinable con precisión. ${ }^{23}$ Esa apariencia de estabilidad, de certidumbre, no se nos rompe sino en aquellos momentos que son sujetos a controversias y contiendas conceptos tales como los de "juventud" o "tercera edad". Al contrario, las categorías de pertenencia social, étnica en Chile y en las sociedades indígenas andinas en particular, soportan un grado alto de inestabilidad y ambigüedad.

Llevando las cosas al extremo, una persona puede por muchas razones sentirse identificado como mapuche, aymara o atacameño: por antecedentes biográficos, no necesaria o exclusivamente los de la sangre, que se integran en una construcción biográfica; por compromiso social, por empatía, hasta por esnobismo (lo "étnico" está de moda). Incluso, y así parecen indicarlo algunos resultados de los Censos de 1992 y 2002, esa persona puede vivir en Punta Arenas, al igual que sus padres y abuelos, sin que ello parezca ocasionar una percepción clara de discrepancia y de necesidad de ajuste. ${ }^{24}$

La autoadscripción étnica es una elección u opción subjetiva aceptada como criterio válido de pertenencia étnica en diversos países (Peyser y Chackiel 1999). En Latinoamérica sería un criterio en ascenso, sea que innove, reemplace o complemente otros criterios como el de la lengua y la localización geográfica (Lavaud y Lestage 2002). Es el que se aplica en Chile durante los dos últimos censos de población. Reemplaza a principios de registro basados en la ubicación geográfica, la residencia y la cultura, donde se apreciaba como

23 Al respecto, se ha hablado de la infancia (Elias 1987 [1936] y 1998 [1980]) y de la juventud (Bourdieu 1990 [1984]) como categorías sociales que orientan las relaciones sociales y la experiencia del sí mismo.

24 La interpretación que hacemos acerca del modo como la gente elabora mentalmente las nociones de cultura y pueblo debe tomarse como una hipótesis de trabajo. Ella no es arbitraria en el sentido de inventada; se sostiene en etnografías de procesos étnicos y desarrollo de identidades colectivas con grupos indígenas, especialmente del norte del país (Gundermann 1999, 2000 y 2003). Es por cierto susceptible de revisión si acaso se verifica inconsistencia interna, o incapacidad de dar cuenta de aspectos importantes hasta ahora no contemplados. indígenas a quienes residieran en "reducciones" mapuche (Pinto 2004 Ms-a, Ms-b, Ms-c, Ms-d, Ms-e, Ms-f; Pérez y Oyarce 2001 Ms: 2). Goza también de importancia en el campo jurídico internacional de los derechos de minorías y pueblos que integran los estados modernos. Algo que suele no enfatizarse mayormente y que se da por sentado, es el supuesto implícito de que a la autoadscripción le acompaña un substrato objetivo que sostiene esa opción subjetiva. ${ }^{25}$ Por lo tanto, para que el procedimiento sea legítimo tiene que acompañarse de fidelidad. ${ }^{26}$ Ambas cuestiones, opción subjetiva y base objetiva unidas son las que dan validez a los resultados. Podremos apreciar que esta convergencia no existe en todos los casos y sus consecuencias son importantes para los fines de "contar indígenas".

Dado que, para fines censales, parecen no cuestionarse mayormente las formas de construcción social de las opciones subjetivas, se sigue asumiendo un modelo de sociedad en el cual las pertenencias sociales objetivas tendrían una correspondencia cerrada con las autoadscripciones subjetivas. Se trata de un a priori social que las instancias gubernamentales referidas asumen como válido.

Esta visión de sociedad y cultura como una totalidad razonablemente coherente e integrada ya no es sustentable; no lo es tampoco para las poblaciones indígenas del país. Esa imagen de sociedad se corresponde bastante bien con las llamadas "sociedades tradicionales" o "culturas" de los

25 Implícito en el Censo de 2002, a pesar de lo que el director del INE señale, en el sentido de que, por diferencia con el censo anterior, ahora sólo se buscaba establecer "la pertenencia a la etnia”. Explícito en el de 1992, donde se buscaba hacer converger "origen étnico" objetivo con declaraciones subjetivas de "pertenencia" (Carta a El Mercurio del 24 de abril de 2003 por parte de M. Aguilera, Director Nacional del INE).

26 Fidelidad de la adscripción con una biografía, con un curso de vida en el cual se hagan presentes antecedentes que autorizan, que le dan validez a la declaración de adscripción étnica. Desde un enfoque de los sujetos deben hacerse presentes construcciones biográficas o formas de elaboración subjetiva de un decurso de vida en el cual la adscripción sea plausible y verosímil. Tales formaciones subjetivas toleran una amplia gama de posibilidades. En cualquier caso, no agotan los recursos subjetivos que sostienen las adscripciones. 
antropólogos. ${ }^{27}$ Pero las sociedades indígenas de hoy son realidades sociales crecientemente complejas, lo que depende en parte de procesos internos, pero también de fuerzas y factores externos que durante el siglo XX, e incluso antes, han inducido dinámicas de deslocalización, fenómenos de diferenciación económica y social, circulación étnica, una mayor desagregación social y heterogeneidad cultural.

En las condiciones anotadas, la lógica de la identificación y las identidades cambia. No es obvio o evidente que una persona o un hogar con antecedentes sociales y culturales mapuche, por ejemplo, tenga que considerarse o autoadscribirse como mapuche. Intervienen en ello la menor capacidad de los grupos locales de origen para imponer trayectorias y proyectos de vida, la mayor movilidad espacial, la fluidez social favorecida por la educación, las migraciones, la vida urbana (hoy mayoritaria, con más claridad entre los pueblos indígenas del norte del país), la persistente vigencia de estereotipos y prejuicios acerca de la personalidad indígena, las problemáticas referencias de sentido que acompañan el concepto de "indio", muy cercano al de "indígena". Todo ello conduce a la institución de lazos y definiciones sociales menos estables, más diversificados, contradictorios muchas veces y además dinámicos. Permite también la permanencia de barreras y reservas para una más libre identificación con "lo indio". Sin pretender agotar el repertorio, en el presente tenemos un abanico de posibilidades de identificación colectiva. En un extremo podemos situar los neo-conservadurismos extremos ${ }^{28} \mathrm{y}$, en el otro, la adopción de diferentes identificaciones sociales (socioprofesionales, urbanas, nacionales, de clase, regionales), con exclusión de las indígenas (mapuche, aymara). Esto último se puede calificar de circulación étnica o, en términos más amplios, de formas de identificación y pertenencia no sujetas a criterios socioculturales (como la de "indio" en la historia colonial y republicana). Pero hay otras vías: la del redescubrimiento de la identidad, las opciones pragmáticas sobre la misma,

27 Quienes la han divulgado junto a otros agentes sociales, tales como profesionales, intelectuales y dirigentes indígenas. Cabría preguntarse por las razones de esta "afinidad electiva".

28 Que, contradictoriamente, no son menos el producto de condiciones modernas que las modalidades de salida de la etnicidad; en algún grado son una respuesta a ellas. las no militantes, entre otras. Desafortunadamente, sabemos más de algunas de las modalidades de adscripción a grupos étnicos por parte de personas de la categoría de los indígenas u originarios, que de las inscripciones en otras identidades sociales, de su diversidad y de la importancia que adquieren en el presente (como la circulación social con salida de lo indígena).

\section{Ambientes y sensibilidades}

Hemos llamado la atención sobre el carácter complejo y dinámico de la relación entre identificación y pertenencia colectiva, particularmente en el caso de las identidades étnicas. De ello resulta que las condiciones mentales de recepción de una pregunta por pertenencia, así como las respuestas a ella por parte de los sujetos interpelados, conlleva una variación que la pregunta, con sus supuestos de base, no es capaz de cubrir y abordar apropiadamente. Vamos ahora a algunos comentarios respecto del ambiente o contexto más general que cubría a los indígenas del país en el momento de los censos que analizamos. Nos preguntamos, entonces, por las sensibilidades existentes sobre la temática indígena, algunas de sus especificaciones y también los cambios que pudieran manifestarse en el periodo intercensal.

Ya para abril de 1992, mes del Censo, el tema del Quinto Centenario del "descubrimiento" de América y las encontradas posturas respecto de aquellos momentos, integraban de un modo destacado la discusión académica y política de y sobre los pueblos indígenas. ${ }^{29} \mathrm{El}$ contexto era ampliamente favorable: América Latina vivía un proceso de redemocratización y florecían las esperanzas de una sociedad más abierta, un ambiente de mayor tolerancia o el compromiso con las libertades. $\mathrm{La}$ conciencia sobre los indígenas se vistió, como en las mejores épocas del indigenismo literario, de ropajes románticos.

El indio de la "new age" aparece simultáneamente como defensor y protector del medio ambiente, portador activo de valores espirituales-religiosos, partícipe integral y cabal de un modo de vida comunitario (Deloria 1998: 154-180) y, en América Latina, símbolo de resistencia contra el capi-

29 Bengoa (1997: 4) se pronuncia en el mismo sentido para el período. 
talismo o la modernización neoliberal. Se difunden imágenes y relatos que parecen apoyar esta visión, como la famosa carta del Jefe Seattle de 1855, claro que en una versión elaborada en 1972 por un guionista de televisión evangélico que tiene significativas diferencias con el texto original. ${ }^{30}$ Sin duda, esto se relaciona también con una tendencia más general a la valoración de lo diferente como exótico, culturalmente distinto, espacialmente lejano y, al mismo tiempo, encarnación de los valores comunitarios perdidos en un hipermodernizado Occidente. Toda esta retórica permea ciertas opciones de consumo, integra corrientes de sensibilidad cultural y proporciona también un ambiente favorable hacia la "causa indígena". Algunos campos de la literatura o el llamado giro cultural de los movimientos sociales de la modernidad tardía, todo ello contribuye con estímulos específicos para inclinarse a solidarizar, a establecer empatía, a sintonizar y a, eventualmente, suscribir una identificación o ser partícipe en algún grado de lo étnico imaginado.

Para el Censo de 2002, el imaginario de lo indígena se había modificado en algún grado, al menos para los dirigentes políticos y de gobierno. En la década anterior, éste se había manifestado ostensiblemente como un actor político y algunos medios de comunicación de masas (mayoritariamente asociados a los intereses del capital) se habían encargado, a su vez, de elaborar una imagen de violentismo, terrorismo étnico, antidesarrollismo, secesionismo, aunque en sectores de izquierda o alternativos persistía la imagen positiva descrita en el párrafo anterior. El "indio" se volvía de carne y hueso, con múltiples demandas, reivindicaciones y luchas que han sido sistemáticamente interpretadas en los términos indicados. Terminando por romper, hasta cierto punto y respecto de algunos sectores de la sociedad, la visión ampliamente favorable dominante en el espacio público a inicios de los ' 90 .

Creemos que lo que hay ahora es una imagen más segmentada. La que los medios han incentivado en los últimos años se encuentra con, o incluso puede verse como, una continuidad de una corriente de representación de lo indígena

30 Ambos textos han sido recientemente recopilados, permitiendo compararlos y confrontar sus diferencias (Grinberg 1999: 17-45) que lo esquematiza en cuanto a su posición en el atraso, no desarrollo y pobreza crónica. No como consecuencia de un efecto estructural históricamente sostenido, sino que más bien por atributos culturales y psicológicos de falta de emprendimiento, conflictividad o círculo vicioso de pobreza.

Estas imágenes están también diferenciadas regionalmente. Si bien para mucha gente del país, la pertenencia a la cultura mapuche no representa un problema y puede llegar a ser atractivo expresar cierto nivel de identificación con ella, por solidaridad, romanticismo o percepción de un origen mestizo, no ocurre lo mismo en regiones. Por ejemplo, la pertenencia a la cultura aymara en la Región de Tarapacá no es la misma que en la ciudad de Santiago; está más cerca de la experiencia diaria de los nortinos (con sus estereotipos, sus aprecios y eventuales conflictos). Ni hablar de la Región de la Araucanía, por parte de los chilenos y extranjeros respecto de los mapuche. Aunque también es un fenómeno presente, en estas regiones es más dudosa la autoadscripción por alguna forma de pertenencia sin una base biográfica plausible. Es dudoso, incluso, que ella se de en una proporción equivalente a la expresión de simpatía por otros grupos étnicos. O también, hacia la propia cultura mapuche en las regiones centrales en el censo de 1992 (Tablas 1, 2 y 3).

\section{Una tipología de formas de pertenencia étnica e identificación}

En función de sistematizar y sintetizar las considerables variaciones detectadas en la autoadscripción étnica, ayudará la presentación resumida de la tipología de pertenencias que hemos elaborado desde el análisis de la información reunida. Es la oportunidad de presentar de un modo ordenado las posiciones de sujeto y las motivaciones implicadas en los actos de adhesión a pertenencias de cultura y pueblo. Cabe, en primer lugar, distinguir entre quienes suscriben pertenencias a culturas $\mathrm{y}$, posteriormente, a pueblos indígenas, de aquellos que realizan declaraciones de no pertenencia. Si introducimos otro principio de clasificación, el de la consistencia biográfica de las adscripciones o no adscripciones de pertenencia cultural y a pueblo, entonces se nos presentan cuatro tipos bien definidos de sujetos con atributos de adscripción exclusivos y excluyentes. 
El primero de los tipos podemos denominarlo el de la pertenencia indígena consistente, o el "indígena coherente" con su historia individual y familiar. Con ello queremos consignar a todos aquellos individuos que declaran pertenencia a cultura o, en su momento, a pueblo, sustentando esa declaración en una construcción biográfica indígena subjetivamente consistente. Como ya hemos indicado, se trata de personas que establecen un vínculo entre su curso de vida y realidades sociológicas reconocibles como indígenas (familia, linaje, grupo local, comunidad). Ese vínculo debe ser definido (no contradictorio y ojalá sin ambigüedades), plausible (posible de haberse dado en la realidad) y verosímil (creíble).

Esas construcciones biográficas se objetivan socialmente $y$, por tanto, se confirman o se discuten en contextos sociales y de interacción donde se hacen intervenir diversos principios y criterios de clasificación social. Los criterios y juicios invocables en uno u otro sentido (adscripción o no) son relativos también a esos contextos sociales. Alguno de ellos en un grupo o zona podrán invocarse con probabilidades de éxito distintas a las de otro contexto étnico; la evolución de un criterio en el tiempo tampoco es desconocida. Cabe agregar a lo anterior el peso creciente que, en materia de normalización de la adscripción social, está teniendo el texto de la Ley Indígena y el ejercicio del reconocimiento jurídico y político de la calidad de indígena ostentado, de acuerdo a ella, por una institución estatal, la CONADI.

Por tanto, lejos de poder considerarlo un tipo empírico homogéneo, es notoria la dispersión de los criterios de atribución, asignación y clasificación como indígenas sobre los que se fundan las autoadscripciones. Los que hemos reconocido claramente son los siguientes. Primero, el parentesco, el reconocimiento de los lazos de "sangre" (consanguinidad), es quizá el criterio con más autoridad a la hora de conocer, reconocer e invocar la condición de indígena. Se es indígena por la sangre. Pero esto resulta todavía genérico si no se puede acompañar de una filiación o genealogía, todo ello en el marco de una historia familiar y de una locación, presente o pasada, en áreas o zonas indígenas.

No puede faltar una alusión somera a los marcadores físicos de reconocimiento de la condición indígena, sin duda asociados al criterio parental. El aspecto físico de las personas (color de la piel, conformación del rostro, fisonomía, aspecto corporal, tipo de pelo, color de ojos, normalmente asociados) sigue funcionando en el país como señal, marcador o indicador de que alguien es o parece "indio". Como es dable suponer, los yerros pueden ser abundantes a medida que las atribuciones son efectuadas por individuos menos adiestrados, pero de lo que no cabe duda es que existe un saber práctico, formado con base en cientos y miles de circunstancias de interacción y comunicación o alusión a lo indígena, de lo que participan indígenas y no indígenas, en el que se van reproduciendo y ajustando criterios y señales de identificación para atribuir la condición de "indio". Se pretende saber, gracias al conocimiento de sentido común (Schutz 1995 [1962]: 35-70), sin saber cómo se sabe, acerca de quien es indígena o no indígena en cada interacción, en cada relación. Así, todo el mundo "sabe", lo cual es más notable en las regiones con sistemas de relaciones intergrupales que son el producto de una ya larga historia como en la Araucanía o en Tarapacá.

La invocación de la residencia en sectores o comunidades reconocidas como indígenas es un criterio bastante socorrido. Tomado por si sólo puede dar origen a muchas arbitrariedades, como parece haber ocurrido con algunos ejemplos del norte del país. Cercano a lo anterior se encuentra la noción de nativo, de nacimiento propio y de los antecesores inmediatos en la localidad, la microrregión o incluso la región. En la mayoría de los casos se opone a inmigrante o afuerino, pero dependiente de los contextos: una cierta cantidad de adscripciones a "colla" y "quechua" provienen de inmigrantes peruanos y bolivianos en cuyas áreas de origen estas nociones son caracterizadoras de todo o parte de la población de esas áreas. Tal atribución puede ser bastante difusa, pues implica asimilaciones de cultura o pueblo con lugar o región de nacimiento, lo que no es obvio o siempre claro.

Los apellidos son utilizados extensivamente como marcador de la condición de indígena, ya sea el paterno, el materno o ambos, por oposición a repertorios no indígenas de los mismos. Mientras que el lugar de origen y la consanguinidad son fácilmente ocultables, es bastante más difícil en- 
cubrir los apellidos. En las zonas indígenas del país hay normalmente población mixta y en las relaciones intergrupales una serie de marcadores personales como los apellidos sirven de señales de reconocimiento de la calidad de indígena y, en el presente, de "rapanui", "aymara" o "mapuche". En los medios urbanos ha sido más frecuente, en el pasado, el cambio de apellidos y el encubrimiento de los orígenes indígenas. Hoy, con la etnificación y etnogénesis en curso, tal conducta es menos común.

Con alguno de los criterios de adscripción centrales por sí solo y, más frecuentemente, en un conjunto, la pertenencia indígena no es por lo general objeto de duda, sospecha o discusión y goza en esa medida de aceptación y reconocimiento por otros indígenas, por no-indígenas y por las instituciones del Estado encargados de la política de acción afirmativa en curso.

Sin entrar en mayores detalles, queremos mencionar algunas de las principales modalidades de identificación indígena presentes en los actos de adscripción censal estudiados. La primera y más importante es aquella de los indígenas que sintiéndose y definiéndose como tales, hacen uso extensivo de los criterios reseñados. Esta ha sido y es todavía, genéricamente hablando, una identificación problemática. Lo es por los juicios negativos y los prejuicios que pesan sobre la condición de indígena desde la sociedad dominante, los mismos que con mucha frecuencia son tácitamente aceptados y no siempre cabalmente discutidos o rechazados por quienes los sufren. Son significaciones problemáticas por la posición que ocupan en un paradigma semántico de la idea de progreso (Gundermann 2003). Es decir, la posición relativa desvalorada que la condición de indígena ocupa en una escala de desarrollo desde lo premoderno, lo tradicional, incluso lo primitivo, hasta lo civilizado, lo desarrollado, lo moderno. Esta desvaloración se encuentra confrontada hoy por una nueva formación discursiva, la del multiculturalismo, que reposiciona lo indígena bajo un nuevo código, el de las culturas, etnias o pueblos originarios. Cada una de estas denominaciones adquiere una dignidad propia a la que le son inherentes ciertos derechos. Estas nociones se han extendido progresivamente $\mathrm{y}$, en esa misma medida, los grupos indígenas se han etnizado. Ya no son las nociones de "raza" o de "indio" las que presiden la autocomprensión de lo indígena, sino que la de grupos socioculturales discretos. ${ }^{31}$

Otra forma habitual de identificación indígena es la del redescubrimiento de la identidad. Participan de ellas quienes no tenían la condición social de indígena como algo que valiera la pena suscribir, que la rechazaban, que tampoco la elaboraban o que, simplemente, no la conocían. Una motivación para el "descubrimiento" es el cambio en el valor de lo indígena etnizado, pero también es una consecuencia de oportunidades (educacionales, de fomento económico, de subsidios) abiertas por la política gubernamental de discriminación positiva. El "descubrimiento" y la suscripción deja de ser lo penosa que podría ser previamente, pudiendo incluso resultar conveniente. Así, una cierta proporción de los fenómenos de adscripción aquí descritos tiene por motivación principal cuestiones muy prácticas (una beca para un hijo, entre las situaciones mejor conocidas); en otros casos, no cabe dudarlo, se fundamentan en valores no directamente materiales, sociales o culturales (el valor de ciertas prácticas de los padres o la importancia del compromiso para con el grupo históricamente excluido), y en inflexiones emocionales. En la mayoría de los casos estas nuevas identificaciones no originan disposiciones a actuar en los términos de una militancia étnica; muy poco más se logra con ellos que una adhesión declarativa o algunos gestos de colaboración. Analíticamente podemos distinguir dos formas de activismo étnico, con frecuencia reunidos en los mismos individuos: la militancia en redes y organizaciones étnicas, por lo común en cerrada relación con la acción del Estado, y lo que hemos calificado de neoconservadurismo cultural. Con esta expresión consignamos tomas de posición identitaria individual donde se hace presente un doble movimiento de depuración. Por una parte, de las creencias y prácticas consideradas ajenas, espurias, introducidas por los conquistadores (las prácticas religiosas cristianas son aquí la piedra de tope). De otra parte, la reelaboración y puesta

31 Para ser más precisos, no es que antes se careciera de una idea de lo indígena como grupos socioculturales. Esa condición era un modo de pensar al "indio" más amplio, que posiciona y privilegia su ubicación atrasada, inculta, no desarrollada por sobre la de unidad sociológica y cultural particular. Hoy el discurso de la pobreza subroga el de atrasado, pero quizá como condición subordinada de una visión de lo indígena como "étnico". 
en práctica selectiva de elementos de la tradición indígena, especialmente la religiosa. ${ }^{32}$ Considérese, por ejemplo, la siguiente afirmación de una estudiante mapuche:

"La responsabilidad de ser mapuche, se cumple al luchar día a día por defender lo nuestro, mantener nuestras costumbres... realizar nuestros deportes, hablar el mapudungun, asumir nuestra organización social y política, todo nuestro mundo aparte" (Manque 1988: 25).

Se trata, claro está, de una estrategia de (re)definición identitaria basada en la purificación cultural, en la cual la adscripción efectiva requiere liberarse de toda la contaminación externa y asumir todo lo propio y distinto, permitiendo a la vez reintegrar al sujeto a su "comunidad perdida" (Lechner 1992): la indígena.

Un segundo tipo de adscripción la hemos calificado de "pertenencia indígena no consistente biográficamente" o, lo que es lo mismo, de "noindígenas solidarios con ellos". Especialmente en el primero de los censos analizados se abrió la posibilidad, por la naturaleza más general de la pregunta, de expresar la comprensión y simpatía que indudablemente sentían, en esos años y sus circunstancias, muchos chilenos hacia los pueblos originarios. El abultado número de autoadscripciones a una cultura indígena en el Censo de 1992, más allá de todo pronóstico, distribuidas homogéneamente en zonas donde no podrían estar presentes en esas magnitudes, podría deberse en parte a una masiva participación de los no-indígenas solidarios. Con ocasión del Censo del 2002, este fenómeno no ha desaparecido, aunque su peso general es menor (Tablas 1, 2 y 3 ).

Se trata entonces de adscripciones no fundadas biográficamente, con un carácter no virtuoso desde el punto de vista de los censos estudiados, que buscaban declaraciones de pertenencia bajo el

\footnotetext{
32 Esto se presenta en jóvenes y adultos jóvenes, hombres y mujeres, con niveles educacionales medios a altos, con prolongadas experiencias urbanas, de todas las etnias; homogeneidad y extensión de la que cabe suponer una corriente de sensibilidades culturales transversal a los distintos grupos, seguramente mucho más amplia que el diámetro de Chile, formulada desde la activa comunicación abierta por la participación indígena y los medios de comunicación.
}

supuesto de que ellas están sustentadas histórica, sociológica y/o culturalmente. En esos casos se estarían haciendo presentes cuatro modalidades de identificación. Una, por solidaridad externa, o empatía con los indígenas, cuyos alcances, podemos suponer, llegan a gestos de este tipo. Otra, en un nivel más desarrollado de adhesión, se funda en un compromiso social y político con los pueblos indígenas y su destino. Por quienes se plantean de este modo, las formas de vida indígenas suelen ser concebidas como modalidades de emancipación social en un mundo de crecientes desigualdades económicas y sociales, ausencia de democracias sustantivas y desorientación e incertidumbre del pueblo. Luego, una tercera, se dirige a las antípodas de lo anterior y corresponde a pertenencias autoatribuidas individualistas, en sintonía con la moda de lo "étnico" que los medios de comunicación han venido promoviendo; está relacionada al mundo del consumo cultural y personal y, por tanto, tiene un carácter efímero, limitado en el tiempo. Una última no es propiamente una identificación con lo indígena, sino con la región de pertenencia. Un cierto número de personas asimiló en 2002 etnia y región, respondiendo desde el todo (p.e., Región de Atacama) a una pregunta por la parte (por el grupo cultural atacameño que es parte de otra región).

Pasamos ahora a aquellos que no suscriben -en el contexto de una interacción censal- algún vínculo con lo indígena. Como en el caso anterior, se nos abren dos posibilidades de formulación de tipos empíricos. El tercer tipo no cabe sino calificarlo de un "indígena subjetivamente disidente". Consideramos aquí los que de un modo resuelto, pero también los que de manera más ambigua, difusa o dudosa, no relevan antecedentes de su historia personal en el marco de una construcción biográfica que los vincula con lo indígena y que, por diversas consideraciones anexas, no se autodeclaran pertenecientes a dicha cultura o pueblo. No sabemos acerca de la cuantía de estos casos, más allá de la sospecha de que podría ser un número relativamente alto, especialmente en los medios urbanos. Una expresión de este fenómeno son los cambios de nombre indígenas en el Registro Civil que, de acuerdo a un estudio realizado hace algunos años, sería de 2365 entre 1970 y 1990 , de los cuales la gran mayoría corresponde a mapuche (2056 casos). En la mitad de ellos, se trata de eliminar el nombre propio mapuche por otro de origen castellano, con el objetivo de- 
clarado de evitar el rechazo, lo que constituiría una forma de "silenciar la discriminación racial" y de autonegación (Llanquileo 1996). ${ }^{33}$

Tratamientos más refinados de la información censal podrían permitir una estimación más detallada de esta situación, donde no están presentes formas de identificación con lo indígena, sino modos de identificación y pertenencia no sujetos a criterios socioculturales como el de "indígena", antes, o "mapuche", "aymara". O también aquellos, más recientes, que participan de otras identificaciones sociales de tipo socioprofesional, urbanas, nacionales, de clase o regionales.

El cuarto tipo, por último, en el que cabe la gran mayoría de la población del país, es el no indígena cuyas declaraciones son consistentes con la ausencia de antecedentes vitales conocidos y subsiguiente construcción biográfica vinculante a lo indígena y que, además, esta materia le resulta indiferente, ajena. No cabe duda acerca de los ancestros mestizos de la mayoría del pueblo chileno, como tampoco de que muchos están concientes de esa realidad. Pero tal cuestión es genérica, abstracta, no conectable con una memoria familiar o genealogía que vincule a su persona y a los miembros de su unidad familiar inmediata. Y, aun si se sospecha acerca de precedentes indígenas posibles de reconocer, por lo general es algo que se obvia o se rechaza de plano.

\section{Resumen y conclusiones}

Nuestro análisis ha intentando mostrar un problema hasta ahora insoluble para quienes elaboran los censos nacionales cuando pretenden contar indígenas. La constatación de las dificultades encontradas en el primer intento, en 1992, los llevó a renunciar, una década más tarde, a basarse en criterios objetivos acerca del número de indígenas presentes en el país, debiendo conformarse con declaraciones de pertenencia. Con ello, los resultados se hacen imprecisos debido a que existen múltiples fuentes de origen para las declaraciones de pertenencia a "pueblo indígena" y con

33 La otra mitad de los casos comprende cambios a otro nombre mapuche. Sin embargo, aún en éstos, se puede colegir que una razón importante es buscar "nombres mapuche que sean menos susceptibles a la mofa de parte del resto de la sociedad no indígena" (Llanquileo 1996). mayor razón, por su carácter más amplio, para la adscripción a una "cultura indígena" 10 años antes. Se vuelven contradictorios porque no es efectivo que esas fuentes de origen de las autoadscripciones étnicas sean equivalentes. Como hemos dicho antes, las preguntas censales se basan en supuestos, a priori sobre la relación entre autoadscripción e identidad que no son corroboradas por el análisis de los procesos sociales distintos, complejos y, en ocasiones, contradictorios implicados en dicha relación. Tener cifras lo más ajustadas y precisas posibles a una base histórica y sociológica objetiva de la pertenencia es indispensable si sobre ellas el Estado quiere fundar decisiones políticas legítimas y técnicas más eficientes.

En esta investigación hemos considerado dos tesis complementarias. La primera afirma que las categorías de "cultura" y de "pueblo" aborigen, indígena $u$ originario refieren, en el imaginario nacional, a entidades cercanas y relacionadas pero también diferentes en cuanto a contenido semántico, generalidad y principios de adscripción. La segunda, por su parte, concierne a la influencia de los factores de contexto y su cambio durante el período ínter-censal: sensibilidades culturales y etnificación e incremento de la conciencia étnica en el marco de formas históricas de identidad/alteridad colectivas en los grupos indígenas nacionales.

Contar indígenas en Chile no es fenómeno nuevo. Lo hizo la administración colonial, al igual que la republicana. Esa contabilización fue adquiriendo un carácter más técnico desde finales del siglo XIX. Contra lo que se creía, durante el siglo XX, el tema no perdió interés para los agentes del Estado, a tono con la persistencia indígena en la formación moderna de las regiones australes, y bajo la constatación de que tardaba en materializarse el pronóstico de la definitiva integración de los indígenas a la masa del pueblo chileno. El que esto último no ocurriera como se esperaba, así como la capacidad de los propios indígenas (a estos efectos, los mapuche) para hacerse presentes y conseguir la creación de leyes e instituciones estatales que atendieran sus asuntos, hace necesario generar información sobre su distribución, número, situación social y problemas. Durante el último siglo, esta historia reconoce dos momentos. Durante la primera mitad del siglo XX primaron criterios objetivistas de identificación 
basados en la residencia y la cultura, dando cabida también a antecedentes de educación, familia y datos sociodemográficos. Estos eran coherentes con el interés de verificar la progresiva integración y asimilación mapuche. Otro, que se abre en 1992 -aunque con el precedente del Censo Nacional de 1952- hace prevalecer uno subjetivo, congruente con las demandas de reconocimiento elaboradas por activos movimientos étnicos y con una política multiculturalista limitada. Por lo tanto, no hay una mejor manera de "contar indígenas". Hay diversas maneras, relativas a los tiempos, los intereses y las posiciones de los agentes que intervienen en los actos de contar (censos u otros cálculos). En Chile, las decisiones sobre esta materia radican principalmente en el INE y, secundariamente, en los agentes de la política indígena de los gobiernos de la concertación (MIDEPLAN, CONADI), organizaciones indígenas y sus líderes o ciertos intelectuales.

El interés en el conteo de indígenas en el Censo Nacional se activa con el retorno a la democracia y la recepción del tema por parte del INE. Con el objeto de esquivar la noción de "pueblo", cuestionada por los sectores políticos de oposición e, inclusive, al interior de la propia coalición de gobierno, la pregunta censal de 1992 fue planteada de forma más neutra, como pertenencia a cultura, $\mathrm{y}$, aparentemente, con mejores posibilidades de ser respondida consistentemente. La respuesta fue notable: alrededor de una décima parte de la población chilena de 14 años y más, declaró pertenencia a alguna de las tres culturas indígenas presentadas en la pregunta. La abrumadora mayoría suscribió la pertenencia a la cultura mapuche. El resultado alcanzado era tanto más sorpresivo cuanto que se encontraba sólo en ciernes la etnificación-etnogénesis que extensivamente ha propiciado la Ley 19.253 o Ley Indígena y la política indígena en general.

Los resultados del Censo de 1992 primero y, más tarde, los obtenidos por la Encuesta CASEN que incluyó una pregunta por pertenencia a "pueblo" indígena, hicieron notar la necesidad de reevaluar la pregunta censal. La reorientación efectuada llevó a que se reafirmara un criterio subjetivo de autoidentificación, en reemplazo de una posible evaluación subjetiva y objetiva a la vez (que se esperaba alcanzar por vía de la consistencia de las auto adscripciones); se reemplazó el concepto amplio y semánticamente complejo de cultura por el más acotado (para fines de autoadscripción) de "pueblo"; se amplió el listado de posibilidades incorporando todos los pueblos indígenas reconocidos (faltaron en 1992 algunos andinos y los fueguinos); la pregunta se hizo universal considerando a todas las personas independientemente de su edad; se sacó la cláusula introductoria que en 1992 habría introducido "ruidos" innecesarios y, por último, la pregunta se mantuvo cerrada, no obstante algunas recomendaciones para introducir especificaciones.

A pesar de los cambios y ajustes, ante una pregunta por pertenencia a cultura o pueblo indígena no quedan suficientemente garantizadas condiciones de emisión homogéneas y unívocas. Ello ocurre por eventuales intereses en juego de los que participan los agentes de la entrevista censal. Por lo demás, esos intereses pueden ser tanto proclives como opuestos a la visibilidad y reconocimiento de los pueblos indígenas (esto último constituye el capital en juego). Se produce también por la presencia de representaciones esenciales, rígidas y tenaces acerca de los indígenas y los no indígenas, surgidas de procesos de racialización presentes en los sistemas de clasificación social de los que participa la población nacional. Por ejemplo, la que asocia "indio" con ciertos atributos físicos e incluso caracteres sicológicos. La entrevista censal es, en realidad, un acto de interacción social y comunicativa considerablemente complejo, en especial porque el contenido del mensaje intercambiado (pertenencia a cultura y pueblo indígena) es polivalente, con coberturas semánticas variables, ambigüas y sujetas a intereses y controversias.

Según el argumento que seguimos, un resultado esperable era que para la noción de cultura se deberían registrar de manera consistente cifras menores que para pueblo, siendo la segunda una adscripción más restrictiva. Y en efecto, así ocurrió. Como se empezó a sospechar con los resultados censales de 1992 y como se pudo apreciar de la encuesta CASEN unos años más tarde, el concepto de cultura convocó mucho más autoadscripción (aproximadamente el doble) que la noción de pertenencia a pueblo. Ello, porque las exigencias en el plano subjetivo de un compromiso de pertenencia son considerablemente más altas en una que en otra alternativa. El concepto de cultura no trae en una medida comparable un reconocimiento como el implicado en la noción de pueblo. Para decirlo de otra manera: el vínculo 
con la pertenencia a pueblo arrastra el costo de una disminución de las autoadscripciones.

Junto a lo anterior, cabía también esperar que los registros salieran de los límites de aquello que denominamos adscripciones basadas en formulaciones biográficas plausibles. La pregunta censal supone que la recepción y respuesta se realice según un principio de fidelidad, idealmente entre un origen social y una declaración de pertenencia o no a un grupo indígena, haciéndola corresponder con él. En realidad, se responde desde una construcción biográfica, subjetiva por definición, que en la mayoría de los casos calza con un origen sociocultural; pero, en otras numerosas ocasiones, esa convergencia simplemente no se realiza. Nos referimos a individuos que teniendo una historia personal objetivamente indígena, se sustraen de una identificación y sentido de pertenencia a esa categoría social. Para que exista una autoadscripción se requiere como mínimo, conciencia de relación con una entidad étnica determinable. En las condiciones sociales y culturales actuales de la población con antecedentes étnicos objetivos, esa conciencia no siempre se da, o esa pertenencia no siempre se acepta. Se elaboran y suscriben otras identificaciones sociales que, cuando se desecha la indígena, lo es en favor de aquellas social y simbólicamente más favorables.

Pero "distorsiones" en sentido contrario también están presentes en uno y otro censo analizado. Los antecedentes étnicos de las biografías personales no guardan correspondencia unívoca con las autoatribuciones de pertenencia. Como señalamos, pueden existir esos antecedentes sin autoatribución; nos encontramos entonces con fenómenos de movilidad social y circulación étnica. $\mathrm{O}$ puede haber autoadscripción sin tales antecedentes, realizados por contingentes importantes de individuos que realizan declaraciones de pertenencia sin que exista una construcción biográfica que la valide; estamos en presencia de fenómenos de solidaridad.

Nuestro argumento apuntó claramente a mostrar la importancia de esta heterogeneidad. Ella ocurre por la pluralidad de posiciones de sujeto y motivaciones desde las cuales los individuos ejecutan actos de respuesta, adhiriendo a pertenencias indígenas o rechazándolas. Debido a la ex- tensión de tales fenómenos, posibles tanto por un contexto favorable (nuevas corrientes y sensibilidades culturales), aunque cambiante, como por la existencia de un arco de modalidades de identificación colectiva, resulta que cuando quieren hacerlo los censos no cuentan sólo indígenas.

Los criterios propuestos por el Censo compiten con principios de clasificación, división e inscripción social vigentes de los que participan censistas y censados. Esos criterios se asientan sobre varios supuestos. Uno de ellos es el de la dinámica objetiva de la cultura. Se presupone para cada pueblo indígena un sistema cultural y de vida compartido más o menos configurado y estable. No cabe poner en duda su existencia, pero sí sus límites y su estabilidad: ¿donde empieza y donde termina el "origen étnico" -su pertenencia objetiva a un sistema cultural- indígena?; ¿a partir de cuándo ya se debe declinar en postular una pertenencia étnica o insistir sobre su posesión?. No es fácil la respuesta, dada la movilidad espacial, la diferenciación y segmentación social, la pluralidad de repertorios culturales que se suscriben, las diferencias generacionales o el desarrollo de tendencias autonomías individuales en que se encuentran envueltos los pueblos indígenas del país.

Durante la década de 1990 y la actual se ha producido un aumento importante de la conciencia étnica, cuestión que se expresa en los fenómenos de etnificación y etnogénesis iniciados entonces. Pero ello no ocurre en el vacío, se elabora desde sistemas de relaciones y clasificaciones sociales formados históricamente. El resultado de conjunto es un significativo crecimiento y también reelaboración de la conciencia de identidad/ alteridad étnicas en los grupos indígenas del país y, por lo tanto, en el conjunto de la población nacional. No obstante, ello no se expresó en las cifras censales por una aparente caída de lo que denomináramos adscripciones por solidaridad. Por otra parte, el reprocesamiento y expansión de esa conciencia de alteridad/identidad conllevaría varios fenómenos asociados: segmentación de las valoraciones sobre los pueblos indígenas y reelaboración de visiones y contravisiones, incremento de un sentido de pertenencia a pueblo en algunos grupos, variaciones regionales significativas y dinámicas de diferenciación identitaria intra grupos. 
Lo anterior refuerza la idea de que los sistemas de asignación a categorías sociales y de identificación son relativos a contextos regionales, a la historia de las estructuras sociales regionales y a formas de relación social (p.e. las urbanas). También hace evidente la condición dinámica y, por ende, cambiante de estos sistemas de clasificación y autoasignación a categorías sociales cuando en los escenarios sociales más amplios tienen lugar cambios e inducciones que favorecen la movilización de las referencias sociológicas, su ajuste o resignificación. Y pueden seguir cambiando en direcciones no predecibles, una vez sueltas las amarras de los sistemas de clasificación social vigentes durante el siglo XX tan fuertemente marcados por la reproducción de un sentido de nación y, a la vez, de negación del "indio".

\section{REFERENCIAS CITADAS}

ALCAMAN, E., 2003 Ms. Censo 2002 y pueblos indígenas. Análisis preliminar cifras nacionales. CONADI, Documento de circulación interna, Temuco.

ALLENDE, S., 1972. Segundo mensaje del Presidente Allende ante el Congreso Pleno. Talleres Gráficos Servicio de Prisiones, Santiago.

ANDERSON, B., 1981. Comunidades imaginadas. Reflexiones sobre el origen y la difusión del nacionalismo. Fondo de Cultura Económica, México D. F.

BARTH, F., 1969. Introduction. En Ethnic groups and boundaries. The social organization of culture difference, F. Barth (Ed.), pp. 9-38. Scandinavian University Press, Oslo.

BENGOA, J., 1997. Los mapuche, comunidades y localidades en Chile. Instituto Nacional de Estadísticas - Ediciones SUR, Santiago.

BOURDIEU, P., 1990 [1984]. La juventud no es más que una palabra. En Sociología y cultura, pp. 163-173. CONACULTA-Grijalbo, México D. F.

BRAND, D., 1941. The peoples and languages of Chile. New Mexico Anthropologist 23: 73-93.

BUSSANI, S., 2003. Mapuche (Chile). El genocidio burocrático. http://www.gfbv.it/3dossier/ind-voelker/mapucheit.html

CALHOUN, C., 1997. Nationalism. University of Minessota Press, Minneapolis.

CAYUN, A., 1991. El censo nacional de población de 1992 y los pueblos indígenas de Chile. Nütram VII (24): 57-59.

COLOMPIL, D., 1972 Ms. Situación de la población indígena de Chile. Algunas líneas de acción en 18 meses de gobierno. Experiencias y posibilidades futuras. Ponencia presentada en el VII Congreso Indigenista Interamericano, Brasilia, 8 de agosto de 1972.
CHACKIEL. J., 1999. A modo de introducción y síntesis. En América Latina: Aspectos conceptuales de los censos de 2000, S. Schkolnik (Ed.), pp. 19-27. CEPAL-CELADE, Santiago.

CONSEJO NACIONAL DE PUEBLOS INDIGENAS DE CHILE (CNPI), 1991. Propuesta de los pueblos indígenas de Chile respecto del Censo Nacional de Población 1992. Nütram VII (24): 61-66.

DELORIA, P., 1998. Playing indian. Yale University Press, New Haven y Londres.

ELIAS, N., 1987 [1936]. El proceso de la civilización. Fondo de Cultura Económica, México D. F.

_ 1998 [1980]. En La civilización de los padres y otros ensayos. Grupo Editorial Norma, Bogotá.

ESPINA, R., A. M. OYARCE, G. PEREZ y R. SANCHEZ, 1998. Población mapuche de Chile. Análisis del Censo de Población de 1992. Instituto de Estudios Indígenas de la Universidad de La Frontera-Instituto Nacional de Estadísticas, Temuco.

ERIKSEN, T. H., 1993. Ethnicity and nationalism. Anthropological perspectives. Pluto Press, Boulder.

FOERSTER, R. y J. I. VERGARA, 2003. Etnia y nación en la lucha por el reconocimiento. Los mapuches en la sociedad chilena. En Mapuches y aymaras. El debate en torno al reconocimiento y los derechos ciudadanos, $\mathrm{H}$ Gundermann, R. Foerster y J. I. Vergara (Eds.), pp. 105177. PREDES - Universidad de Chile, Santiago.

GRINBERG, M., 1999. Cartas por la tierra. Errepar, Buenos Aires.

GUNDERMANN, H., 1999. Categorías de identidad en el discurso popular urbano del norte de Chile. Estudios Atacameños 17: 25-32.

2000. Las organizaciones étnicas y el discurso de la identidad en el norte de Chile, 1980-2000. Estudios Atacameños 19: 75-91. 
2003. Las poblaciones indígenas andinas de Chile y la experiencia de la ciudadanía. En Mapuches y aymaras. El debate en torno al reconocimiento y los derechos ciudadanos, H Gundermann, R. Foerster y J. I. Vergara (Eds.), pp. 9-104. Ril Editores, PREDES - Universidad de Chile, Santiago.

GUNDERMANN, H., R. FOERSTER y J. I. VERGARA, 2004 Ms-a. Autoadscripción étnica en Chile, los resultados censales de 1992 y 2002, San Pedro de Atacama.

—_2004 Ms-b. Autoadscripción étnica de los pueblos andinos de Chile analizada a través de las cifras censales de 1992 y 2002, San Pedro de Atacama.

HANNERZ, U., 1992. Cultural complexity. Studies in the social organization of meaning. Columbia University Press, Nueva York.

-1998. Conexiones trasnacionales. Cultura, gente, lugares. Frónesis-Cátedra, Universidad de Valencia, Madrid.

INSTITUTO NACIONAL DE ESTADISTICAS (INE), 1992. Resultados Generales Censo de Población y Vivienda Chile 1992. Instituto Nacional de Estadísticas, Santiago.

-2002a. Síntesis de resultados. Instituto Nacional de Estadísticas, Santiago.

-2002b. Censo 2002. Resultados Población y Vivienda: País-Región-Provincia-Comuna. Versión en CD. Instituto Nacional de Estadísticas, Santiago.

JARA, A., 1956. Legislación Indigenista de Chile. Ediciones Especiales del Instituto Indigenista Interamericano, México D. F.

JEANNOT, B., 1972. El problema mapuche en Chile. Cuadernos de la Realidad Nacional 14: 5-14.

LAVAUD, J. P. y F. LESTAGE, 2002. Contar los indígenas: Bolivia, México, Estados Unidos. Tinkazos 13: 37.

LECHNER, N., 1992. La búsqueda de la comunidad perdida. Los retos de la democracia en América Latina. Sociológica 19: 11-29.

LLANQUILEO, M. C., 1996. La identidad cultural en los procesos de modernización. Un análisis de los cambios de nombres en sujetos mapuche, 1970-1990. Proposiciones 27 (www.sitiosur.cl)

MANQUE, C., 1988. La responsabilidad de ser mapuche. Nütram IV (2): 25-26.

MARTINEZ, J. y M. PALACIOS, 1996. Informe sobre la decencia. Ediciones SUR, Santiago.

MILES, R., 1989. Racism. Routledge, Kent.

OYARCE, A. M., M. ROMAGGI y A. VIDAL, 1989. Cómo viven los mapuche. Análisis del Censo de Población de Chile 1982. PAESMI, Santiago.
PEREZ, G. y A. M. OYARCE, 2001 Ms. Informe Final Proyecto: Investigación operacional para la propuesta de preguntas relativas a grupos étnicos en censos e instrumentos de medición. Instituto de Estudios Indígenas, Universidad de la Frontera, Temuco.

PEYSER, A. y J. CHACKIEL, 1999. La identificación de poblaciones indígenas en los censos de América Latina. En América Latina: Aspectos conceptuales de los censos de 2000, S. Schkolnik (Ed.), pp. 353-363. CEPALCELADE, Santiago.

PINTO, J., 2004 Ms-a. El Censo chileno de 1907. Departamento de Ciencias Sociales, Universidad de la Frontera, Temuco.

2004 Ms-b. El Censo de población de la República de Chile de 1920. Departamento de Ciencias Sociales, Universidad de la Frontera, Temuco.

_2004 Ms-c. El Censo chileno de 1930 y la población "Araucana". Estimaciones globales. Departamento de Ciencias Sociales, Universidad de la Frontera, Temuco.

-2004 Ms-d. El Censo chileno de 1952. Departamento de Ciencias Sociales, Universidad de la Frontera, Temuco.

_2004 Ms-e. El Censo chileno de población y vivienda de 1960. Departamento de Ciencias Sociales, Universidad de la Frontera, Temuco.

2004 Ms-f. Censos e imaginarios en Chile en el siglo X. Departamento de Ciencias Sociales, Universidad de la Frontera, Temuco.

_2005 Ms. El censo de 1940. En La población de la Araucanía en el siglo XX. Informe Final Proyecto FONDECYT 1020289, Temuco.

SCHUTZ, A., 1995 [1962]. El problema de la realidad social. Amorrortu, Buenos Aires.

SIMMEL, G., 1977 [1908]. Sociología 1. Estudio de las formas de socialización. Alianza Editorial, Madrid.

UNIVERSIDAD DE LA FRONTERA, INSTITUTO NACIONAL DE ESTADISTICAS, PROGRAMA DE APOYO Y EXTENSION EN SALUD MATERNO INFANTIL, CENTRO LATINOAMERICANO DE DEMOGRAFIA, 1990. Censo de reducciones indígenas seleccionadas: análisis sociodemográfico, IX Región-Chile 1988, Santiago.

VALDES, M., 1998. Hipótesis para aproximarse a la cuestión mapuche a través del censo y un adendum. Publicaciones Editorial Digital Ñuke Mapu, http:/www.soc.uu.se/ mapuche

-2003 Ms. Reflexiones metodológicas en torno al censo de 1992 y 2002: El caso mapuche en la Región Metropolitana. Ponencia presentada en el Seminario Internacional "Derechos humanos y pueblos indígenas: Tendencias internacionales y realidad local”, 20 -22 de julio de 2003, Temuco. 


\section{CONTAR A LOS INDIGENAS EN CHILE..}

VALENZUELA, R., 2002 Ms. Análisis comparado del impacto de las políticas públicas sobre la población indígena en Chile, según las encuestas CASEN 1996 y 2000. Documento preparado para el Grupo de Trabajo Desarrollo Económico y Social de la Comisión de Verdad Histórica y Nuevo Trato, Santiago.

VERGARA, J. I., A. ARAVENA, M. CORREA y R. MOLINA, 1999. Las tierras de la ira. Los sucesos de
Traiguén y los conflictos entre comunidades mapuche, empresas forestales y Estado. Praxis 1: 112-128.

\section{Periódicos}

El Mercurio 20 de abril de 2003; 24 de abril de 2003; 30 de abril de 2003. 
